Discussion Papers

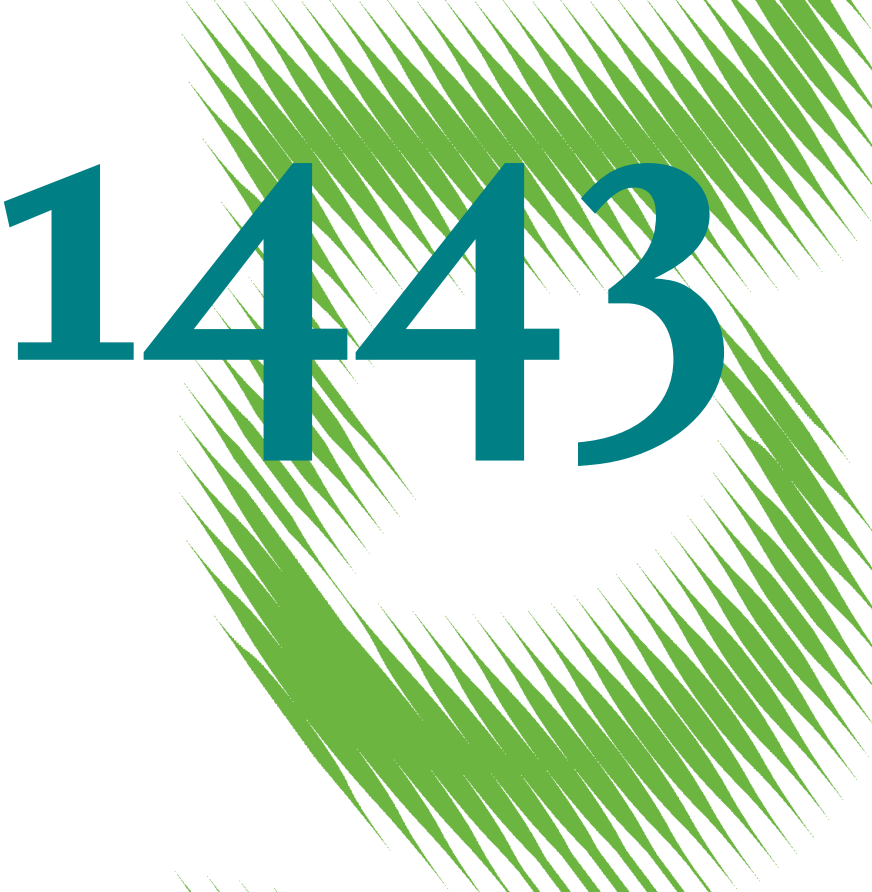

Reducing Binge Drinking?

The Effect of a Ban on Late-Night

Off-premise Alcohol Sales on Alcohol-

Related Hospital Stays in Germany 
Opinions expressed in this paper are those of the author(s) and do not necessarily reflect views of the institute.

IMPRESSUM

(C) DIW Berlin, 2015

DIW Berlin

German Institute for Economic Research

Mohrenstr. 58

10117 Berlin

Tel. +49 (30) $89789-0$

Fax +49 (30) $89789-200$

http://www.diw.de

ISSN electronic edition 1619-4535

Papers can be downloaded free of charge from the DIW Berlin website:

http://www.diw.de/discussionpapers

Discussion Papers of DIW Berlin are indexed in RePEc and SSRN:

http://ideas.repec.org/s/diw/diwwpp.html

http://www.ssrn.com/link/DIW-Berlin-German-Inst-Econ-Res.html 


\title{
Reducing binge drinking? The effect of a ban on late-night off-premise alcohol sales on alcohol-related hospital stays in Germany
}

\author{
Jan Marcus* and Thomas Siedler ${ }^{\dagger}$
}

\begin{abstract}
Excessive alcohol consumption among young people is a major public health concern. On March 1, 2010, the German state of Baden-Württemberg banned the sale of alcoholic beverages between $10 \mathrm{pm}$ and 5am at off-premise outlets (e.g., gas stations, kiosks, supermarkets). We use rich monthly administrative data from a 70 percent random sample of all hospitalizations during the years 2007-2011 in Germany in order to evaluate the short-term impact of this policy on alcohol-related hospitalizations. Applying difference-in-differences methods, we find that the policy change reduces alcohol-related hospitalizations among adolescents and young adults by about seven percent. There is also evidence of a decrease in the number of hospitalizations due to violent assault as a result of the ban.
\end{abstract}

JEL: I12, I18, D04

Keywords: Binge drinking, drinking hours, alcohol control policies, difference-in-differences, hospital diagnosis statistics, alcohol

*Jan Marcus, DIW Berlin, Mohrenstraße 58, 10117 Berlin, Germany. E-mail: jmarcus@diw.de.

†Thomas Siedler, Universität Hamburg, Von-Melle-Park 5, 20146 Hamburg. E-mail: Thomas.Siedler@wiso.uni-hamburg.de. 


\section{Introduction}

According to the World Health Organization (2014), excessive alcohol consumption is responsible for around 3.3 million preventable deaths worldwide in 2012, and the harmful use of alcohol accounts for 5.1 percent of the global burden of disease and injury. In particular, excessive consumption of alcohol by young people is a major public health concern. The Centers for Disease Control and Prevention reports that in 2010, among U.S. adults aged 18 years and older, binge drinking prevalence and intensity was highest among those aged 18-24 years (Kanny et al. 2012). Since drinking is habit-forming (see e.g. Enoch 2006), early drinking onset might have long-lasting adverse consequences. Indeed, a large body of literature documents a significant relationship between (extensive) alcohol consumption in young people and various negative outcomes, such as crime (Carpenter 2005a), risky sexual behavior and teenage pregnancy (Sen 2003; Carpenter 2005b), suicide (Birckmayer and Hemenway 1999; O'Connell and Lawlor 2005), lower academic performance (Carrell et al. 2011), lower employment and higher risk of unemployment (Mullahy and Sindelar 1996), adverse health effects such as mortality and hospitalization (Chaloupka and Xu 2011; Kim et al. 2012), and motor vehicle fatalities (Ruhm 1996; Dee 1999).

High-risk drinking has been increasing in the last years among young people in the United States (White et al. 2011) and across much of Europe, including Germany (DHS 2008). Figure 1 reports trends in alcohol-related hospitalization rates among adolescents and young adults in Germany, a country where young people can legally buy beer and wine starting with the age of 16 . Panel a) displays trends in the annual number of alcohol-related hospitalizations per 100,000 inhabitants of the same age between 2002 and 2011. Panel b) displays the corresponding growth rates. The figure shows that the alcohol-related hospitalization rates doubled in the age groups 15-19, 20-24, and 25-29. The German Federal Statistical Office reports that in 2011, 41,959 individuals between 15 and 29 received hospital treatment due to excessive alcohol consumption, compared to 18,391 in $2002 .^{1}$

In March 2010, the German state of Baden-Württemberg ${ }^{2}$ banned the sale of alcoholic beverages between 10pm and 5am at off-premise outlets (e.g., gas stations, supermarkets, kiosks). One of the law's main objectives was to reduce binge drinking among young people. This study presents first evidence on the short-term effects of this late-night

\footnotetext{
${ }^{1}$ https://www.destatis.de/EN/FactsFigures/SocietyState/Health/Hospitals/Tables/ DiagnosisAlcoholAgYears.html. Note that the numbers of alcohol-related hospitalizations in Figure 1 are taken from the same source. Accessed on July 16, 2014.

${ }^{2}$ Baden-Württemberg is located in southwestern Germany and is the third-largest German state by population (10.5 million in 2011).
} 
alcohol sales ban on alcohol-related hospitalizations. We exploit rich monthly data from a 70 percent random sample of the German hospital diagnosis statistics for the 2007-2011 period. This nationwide hospitalization data set contains information about all inpatients at all German hospitals. We study the short-term effect of the reform on alcohol-related hospitalizations in general and specifically for young people, as there are various reasons to assume that the reform impacts youth in particular. Using an additional data set from one large hospital in the comparison group, we also document that the majority of alcohol-related hospital admissions among young people takes place in late evening and during the night. Hence, the late-night alcohol ban is likely to be most binding for adolescents and young adults.

Indeed, we find that the policy change reduces alcohol-related hospitalizations among adolescents (ages 15-19) and young adults (ages 20-24) by about seven percent. For older individuals, there is no empirical evidence of a significant reduction. Our findings are robust to alternative definitions of the control group (e.g., only states in western Germany, only the southern states of Bavaria and Hesse, a synthetic control group), different restrictions of the sample, the addition of further control variables (e.g., county-specific time trends) and various estimation issues (e.g., estimation in logs, Tobit model). We provide evidence that the ban impacts both male and female adolescents/young adults, though the effect is stronger for males. Furthermore, we find empirical evidence that the latenight off-premise alcohol sales ban reduces overall hospitalizations due to diagnoses that are often related to violent assaults. However, we do not find evidence of complementary effects on illicit drug use, as the ban does not decrease drug-related hospitalizations.

Overall, our empirical results suggest that the late-night off-premise alcohol ban is an effective policy strategy for reducing excessive alcohol consumption among adolescents and young adults. Hence, the ban can work as a measure against negative externalities of excessive alcohol consumption, such as violence, traffic accidents, and noise (Parry et al. 2009) and as a commitment device for individuals with time-inconsistent preferences (Hinnosaar 2012). The empirical findings contribute to the literature on whether and how policies can influence problematic drinking behaviors. The results are also informative for policy makers in other countries who are considering or planning to implement similar late-night alcohol sales bans: the investigated ban can be considered to be a fairly "light touch" regulation compared to other alcohol control policies, as it restricts the sale of alcoholic beverages only at a specific time of the day (10pm to $5 \mathrm{am}$ ) and only for a specific type of outlet (off-premise outlets).

The outline of the paper is as follows. Section II discusses the literature on related alcohol control policies, Section III provides background information on the late-night ban and other relevant alcohol policies in Germany, and Section IV describes the data. 
Section V discusses the empirical approach, and the main results are presented in Section VI. Section VII probes the robustness of the findings and Section VIII reports further results (e.g., effect heterogeneity, evolution of the treatment effect, length of hospital stay, and other diagnoses). Section IX concludes.

\section{Related literature}

Proponents of alcohol control policies often point out that excessive alcohol consumption is a negative externality as it can compromise others either directly (as, e.g., in the case of crime, traffic accidents, and noise) or indirectly (e.g., through higher costs for the health care system). Additionally, alcohol control policies are often justified with reference to time-inconsistent preferences of alcohol consumers (Hinnosaar 2012). For instance, in the morning, individuals with time-inconsistent preferences may plan to drink less or no alcohol that evening, but when evening comes, they find themselves unable to resist the urge for a drink. Therefore, a ban on late-night alcohol sales can be seen as a kind of commitment device for individuals with time-inconsistent preferences (Bryan et al. 2010): during the day they plan to consume fewer beverages in the night and therefore purchase less alcohol during the day, but when the night arrives, they go to the shop again to buy more alcohol (for a formalized version of this argument, see Hinnosaar 2012). The late-night ban on alcohol sales can prevent this additional shopping trip.

In general, one can distinguish among several regulatory strategies for restricting access to alcohol: (i) regulating temporal access (e.g., hours and days of sale); (ii) regulating the economic access (e.g., price policies and alcohol taxes) ${ }^{3}$ (iii) regulating demographic access (e.g., minimum legal drinking ages, drunk driving laws) ${ }^{4}$ and (iv) regulating the locations where alcohol is sold (e.g., on- versus off-premise outlets, public events). ${ }^{5}$

The literature most closely related to ours investigates restrictions in temporal access to alcohol. These studies analyze how changes in the hours and days of alcohol sales affect consumption, hospitalizations, traffic fatalities, and crime (Norström and Skog 2005; Vingilis et al. 2005; Chikritzhs and Stockwell 2006; McMillan and Lapham 2006; Vingilis 2007; Middleton et al. 2010). Vingilis (2007), Popova et al. (2009) and Middleton et al.

\footnotetext{
${ }^{3}$ Overall, the literature on regulating economic access to alcohol finds that alcohol consumption decreases with rising prices and that raising alcohol taxes is effective in preventing alcohol-related problems (Grossman et al. 1993; Manning et al. 1995; Ruhm 1996; Dee 1999; Cook and Moore 2000, 2002; Young and Bielinska-Kwapisz 2006; Carpenter et al. 2007; Wagenaar et al. 2009, 2010; Chaloupka and Xu 2011).

${ }^{4}$ Most of the research on policies that restrict demographic access to alcohol focuses on minimum legal drinking ages in the United States (Carpenter et al. 2007; Lovenheim and Slemrod 2010; Carrell et al. 2011). The general consensus in this literature is that the introduction of the minimum legal drinking age of 21 was effective in reducing the prevalence and intensity of drinking (Wagenaar and Toomey (2002), Carpenter et al. (2007) and references therein).

${ }^{5}$ See, for example, Scribner et al. (1995) and Speer et al. (1998).
} 
(2010) provide recent surveys on the effects of changes in hours and/or days of alcohol sales on alcohol consumption and alcohol-related harm. Newton et al. (2007) examine the impact of the UK licensing law that came into effect in November 2005 and that made the opening hours for licensed premises more flexible. Using data from March 2005 and March 2006 from one emergency hospital in London, the study finds that the proportion of alcohol-related assaults resulting in overnight hospitalization increased by roughly one percentage point, alcohol-related hospital admission rates by nearly two percentage points, and alcohol-related injuries by 2.5 percentage points. Norström and Skog (2005) study the impact of Saturday openings of alcohol retail shops in Sweden on alcohol sales, assaults, and drunk driving. The authors exploit both time and regional variation in Saturday openings of alcohol retail shops. First, in February 2000, a trial phase started during which six counties implemented Saturday openings, followed by an extension across the whole of Sweden in July 2001. The authors report that alcohol sales increased by nearly four percent due to this change in trading days, but they find no effects on various assault indicators and mixed effects for drunk driving. Vingilis et al. (2005) study the Liquor Licence Act in Ontario, Canada, that extended on-premise alcohol sales from 1am to 2am in Ontario. Their findings suggest that the slight extension in opening hours contributed to a slight increase in drinking-related problems in some areas of Ontario.

Closely related to our study is an analysis by Wicki and Gmel (2011). The authors examine a similar ban on late-night alcohol sales in the Swiss canton of Geneva, but were unable to disentangle the effects of the late-night alcohol sales ban from those of a general ban on alcohol sales in gas stations and video stores, which came into effect at the same time. They found major decreases in alcohol-related hospitalizations in the canton of Geneva due to the joint effect of these reforms (e.g., a reduction of 40 percent in alcohol-related hospitalizations among teenagers). Yet, it remains unclear whether this large decrease is due to the late-night alcohol sales ban, to the general ban on alcohol sales at gas stations and video stores, or to both bans.

To date, there exists inconclusive evidence in the literature on the effectiveness of limiting the hours of off-premise alcoholic sales. Indeed the Task Force on Community Preventive Services in the United States concludes: "The Task Force found insufficient evidence to determine the effectiveness of increasing existing limits on hours of sale at offpremise outlets, because no studies were found that assessed such evidence" (Task Force on Community Preventive Services 2010: 606). Our study aims at filling this gap in the literature by studying a recent legislative change in hours of alcohol sales in Germany. 


\section{Institutional background}

The policy change that we analyze bans the sale of alcoholic beverages between 10pm and $5 \mathrm{am}$ at off-premise outlets (e.g., gas stations, supermarkets, kiosks) in the German state of Baden-Württemberg. The law has two main intentions: to reduce binge drinking (especially among young people) and to reduce alcohol-related violence and harm. The draft bill was submitted on July 21, 2009 (Landtag von Baden-Württemberg 2009b), and discussed for the first time in the state parliament on July 30, 2009 (Landtag von BadenWürttemberg 2009c). During these consultations, Heribert Rech, Minister of the Interior in Baden-Württemberg, explained the aims of the law as follows: "The aim is clear: With this law, we want to combat alcohol-related crime at night, and we want to protect adolescents and young people in particular from alcohol-induced health risks. These risks are especially high when they are able to consume alcohol at night" (Landtag von BadenWürttemberg 2009c: 5258). The law was approved by the state parliament on November 4, 2009, and went into effect on March 1, 2010 (Landtag von Baden-Württemberg 2009a).

Violating the ban results in a fine of up to 5,000 euros. There are reasons to assume that the police immediately began enforcing the ban given that this was their preferred policy (see Landtag von Baden-Württemberg 2009b). Furthermore, when reviewing newspapers published around the time of the ban's introduction, we found little evidence of complaints about a lack of enforcement.

Before the ban came into effect, it was theoretically possible to buy alcoholic beverages 24 hours a day at off-premise outlets. Gas stations were the main place that people could buy alcohol around the clock. Therefore, both the public debate on the law and the reasoning for its introduction focused primarily on gas stations (Landtag von BadenWürttemberg 2009b). Since the ban applied solely to off-premise sales, bars, restaurants, and other on-premise outlets were not affected.

The ban on late-night off-premise alcohol sales can be considered as a fairly "light touch" regulation compared to other alcohol control policies. Unlike a general prohibition, the ban only regulates the purchase, not the consumption of alcohol. In contrast to alcohol taxes, it is easy to legally avoid the ban, e.g., by buying the alcohol before 10pm (i.e., pre-stocking). Moreover, unlike minimum legal drinking age regulations, the ban does not exclude entire demographic groups from the legal consumption of alcohol. Compared to other policies regulating the temporal access to alcohol, the ban neither prohibits the off-premise sale of alcohol for entire days nor does it regulate the purchase of alcoholic beverages on-premise.

The basic argument why the ban might nevertheless be effective is that it suppresses the spontaneous purchase of alcohol at off-premise outlets. It functions by complicating 
access to alcoholic beverages in situations when those who have already begun consuming alcohol might otherwise continue to do so in an abusive and unhealthy way (Landtag von Baden-Württemberg 2009b: 11, 13-14). ${ }^{6}$ In such situations, the ban can be seen as an interruption in the alcohol supply chain as it increases the effort needed to consume more alcohol. The ban can be also considered as a commitment device for individuals with time-inconsistent preferences. As such, the law might be very effective in curbing binge drinking, as it restricts access to alcohol at a crucial time of the day when the overwhelming majority of excessive drinking takes place.

Figure 2 displays the distribution of hours of alcohol-related hospitalizations by age groups. $^{7}$ The histograms for individuals aged 15-19 and 20-24 show that the majority of alcohol-related hospital admissions in these age groups occur in the late evening and at night. Among adolescents (ages 15-19), around 70 percent of all alcohol-related hospitalizations take place between 10pm and 4am. Similarly, among young adults (ages 20-24), nearly one in two admissions happens during these hours. For other age groups, however, there is no similar peak between $10 \mathrm{pm}$ and $4 \mathrm{am}$. In contrast, the histogram for all individuals (Panel a) in Figure 2) shows that many admissions take place in the morning hours, which is mainly driven by individuals aged 30 and above (Panel e). For example, among those aged 30 and above, those who are admitted to hospital between 8am and 11am are more likely to be male ( 82 percent compared to 78 percent), to be older (56 years vs. 51 years), to stay longer in hospital, to be operated, and to be admitted to hospital during the week. ${ }^{8}$

The study by Bouthoorn et al. (2011) also reports that the majority of alcohol-related hospitalizations among adolescents in the Netherlands happen in the late evening and at night. These findings suggest that banning late-night off-premise alcohol sales could be more effective at curbing binge drinking and preventing alcohol-related harms, especially among young people, than limiting alcohol sales to certain days of the week, for instance, through Sunday liquor laws (Stehr 2010; Heaton 2012).

We expect the ban to have a particularly strong impact on young individuals for several reasons. First, the ban is likely to be most binding for youth and young adults, as most of their excessive drinking takes place in the evening and during the night. Second, young people might be less likely to buy alcohol ahead of time and store it for later consumption.

\footnotetext{
${ }^{6}$ This argument is based on the assumption of alcohol being a (harmful) addictive good: the marginal utility of current consumption rises with the amount of past consumption (reinforcement), the amount of past consumption lowers utility (tolerance), and current consumption is associated with a positive marginal utility (withdrawal) (see e.g. Becker and Murphy 1988; Cawley and Ruhm 2012).

${ }^{7}$ The data come from one large hospital in the control group (i.e., outside of Baden-Württemberg) and contain more than 14,000 alcohol-related hospitalizations in the period 2007-2013.

${ }^{8}$ Doctors working in emergency rooms in hospitals told us that a high proportion of alcohol-related hospital admissions in the morning hours are elderly homeless people, who are often alcoholics.
} 
Often young people do not have their own apartments or other personal spaces where they could safely store alcohol. Third, the ban was justified by arguments that young people often use gas stations as gathering points and to buy alcohol for "predrinking" (Landtag von Baden-Württemberg 2009b: 8,11). Fourth, young individuals might be less likely to go to bars, where alcohol is more expensive. This may be particularly salient for young individuals with their limited budgets. Furthermore, the German Law for the Protection of the Youth (Jugendschutzgesetz) regulates the hours during which children and adolescents are allowed to enter bars and pubs: children below the age of 16 can visit bars and pubs only accompanied by a parent or legal guardian; young people aged 16 or 17 must leave at midnight unless accompanied by a parent or legal guardian. Additionally, minimum legal drinking ages are more tightly enforced in bars and pubs (Landtag von Baden-Württemberg 2009b).

The reasoning for why the ban should be effective in reducing excessive alcohol consumption is based on the assumption that alcohol purchased at night tends to be consumed relatively shortly after its purchase. Several arguments can be made in favor of this assumption. First, the ban primarily affected gas stations as not all supermarkets in the treatment state are open after $10 \mathrm{pm}$ and alcohol is considerably more expensive at gas stations than at supermarkets. Hence, if young people were planning to consume the alcohol later-for example, the next day-they could simply wait and buy the alcoholic drinks at a lower price at the supermarket. Second, evidence has been reported in newspaper articles that many young people tend to consume alcohol immediately or shortly after purchasing it (Hoffmann 2009; Hoischen and Eppelsheim 2009). ${ }^{9}$

The advantage of the German setting for a clean analysis of the reform's effect is that many of the other regulations that might impact alcohol-related hospitalizations are federal laws and thus constant across states. Examples include drunk driving laws, alcohol taxes, and youth protection laws. Also minimum legal drinking ages do not differ between the states. Germany has relatively nonrestrictive laws regulating alcohol purchases and consumption, with three different legal minimum drinking ages. ${ }^{10}$ Children under the age of 14 are not allowed to consume or purchase alcohol. Children aged 14-16 are allowed to consume undistilled alcoholic beverages, such as beer and wine, if they are in the company of a parent or legal guardian. Youth aged 16-18 are allowed to drink beer and wine without parental consent and without being accompanied by a legal guardian, but no hard liquor or spirits. As soon as young people turn 18, they are allowed to drink all

\footnotetext{
${ }^{9}$ For example, an article in the daily newspaper Der Tagesspiegel with the title "Pre-drinking at the gas station" (Vorglühen an der Tankstelle) describes the problem that young people drink excessively in front of gas stations (Hoffmann 2009).

${ }^{10}$ Drinking ages are regulated by $\$ 9$ of the German Law for the Protection of the Youth (Jugendschutzgesetz).
} 
alcohol beverages.

There are, however, a few potentially relevant laws that differ between states and over time. A large-scale reform of the German federal system in 2006 (Föderalismusreform I) transferred legislative competence for shopping hours from the federal to the state level. Following this reform all of the states (except Bavaria) enacted their own laws on shopping hours that went into effect between November 2006 and July 2007. ${ }^{11}$ All changes in opening hours took place about three years before the late-night alcohol sales ban that we analyze here. However, in order to rule out potential effects of these policy changes, we include a set of dummy variables capturing the effect of different shopping hour regimes. In the robustness section, we also restrict our analysis to a period without changes in the shopping hours of any state.

Furthermore, bar hours differ between states. There is more variation within than between states, however, as most states leave it up to the municipalities to regulate bar hours. On January 1, 2010, Baden-Württemberg changed the general legal closing time of bars, clubs, and restaurants from $2 \mathrm{am}$ to $3 \mathrm{am}$ on weekdays and from $3 \mathrm{am}$ to $5 \mathrm{am}$ on weekends. Municipalities were still allowed to extend or reduce the general closing hours. As there is some evidence in the literature (e.g., Newton et al. 2007; Vingilis 2007) that extended bar hours might slightly increase extensive alcohol consumption, we might be underestimating the effect of the late-night ban on off-premise alcohol sales, which came into force two months after the extension of the legal bar hours. ${ }^{12}$

We also checked for other potentially relevant alcohol-related initiatives that might differ between states. However, these campaigns were either implemented in the whole of Germany and/or implemented clearly before the introduction of the ban or after the period of our analysis (e.g., "Don't drink too much - Stay Gold", "HaLT - Hart am Limit", "Null Alkohol - Voll Power"). For example, "Don't drink too much - Stay Gold" was initiated nationwide in 2008 and aims at tackling excessive alcohol consumption among young people with informational videos and posters. ${ }^{13}$ Similarly, "HaLT" is a nationwide initiative aimed at preventing alcohol addiction implemented across all states. It offers children and adolescents who have experienced alcohol-related hospitalizations counseling and group discussions. Today, there are around 170 local HaLT initiatives throughout Germany. ${ }^{14}$ Overall, it is unlikely that these various alcohol campaigns bias our results.

\footnotetext{
${ }^{11}$ Most states have extended shopping hours to 24 hours a day six days a week (except Sundays). Some states, however, limited weekday opening hours to $6 \mathrm{am}$ to $8 \mathrm{pm}$ (Saarland, Bavaria) or 6am to 10pm (Saxony, Rhineland-Palatinate).

${ }^{12} \mathrm{We}$ discuss this issue in more detail in the robustness section.

${ }^{13}$ See http://www.staygold.eu/. Accessed on June 2, 2014.

${ }^{14}$ See http://www.halt-projekt.de for further information. Accessed on June 2, 2014.
} 


\section{Data}

We use data from the German hospital diagnosis statistics for the years 2007-2011 (FDZ 2014). These nationwide hospitalization statistics are a very rich source of data providing information about all inpatients in all German hospitals (excluding police hospitals and hospitals of the penal system). Inpatients in the German context also include individuals who receive treatment in the emergency department but do not stay overnight. ${ }^{15}$ Due to data confidentiality regulations, we work with a 70 percent random subsample of all hospitalizations.

This data set has three main strengths. First, the sample size is extremely large (e.g., about 13 million hospitalizations are recorded in our 70 percent subsample for the year 2011). Second, as the data are not self-reported, we do not have to worry about panel attrition, social desirability bias, and the like. Third, while other data sets on alcohol consumption provide information only on an annual basis, this data set allows us to identify the relevant outcome on a monthly basis. This is crucial as the ban did not start at the beginning of a year. Furthermore, the monthly basis allows us to distinguish the effect of the ban on alcohol sales from other changes that took place in the same year (but not in the same month).

The data set has some shortcomings, as well. First, for each patient, it only includes information about the main diagnosis and a few demographic variables (age, gender, county of residence), but no socio-economic variables. This is not a major concern for the present analysis, which focuses on the average effect of the reform. Yet it prevents us from analyzing whether the reform had differential effects on specific socio-economic groups. Second, because the data contain only the main diagnosis for each patient, the number of alcohol-related hospitalizations may be underestimated. For instance, an individual who suffered a physical injury (e.g., laceration) due to excessive alcohol consumption might not be classified based on alcohol intoxication but based on the injury (Stolle et al. 2010). ${ }^{16}$ This kind of misclassification might result in an underestimate of the policy reform's effect. ${ }^{17}$ Third, the latest available hospitalization information is from December 2011 because the data collection process is quite complex: the data are submitted by the individual hospitals, checked by the statistical offices of the German states, and distributed by the German Federal Statistical Office. Hence, we can only analyze short-term consequences of the reform (with 22 months of post-policy information).

\footnotetext{
${ }^{15}$ In contrast to the United States, emergency rooms outside of hospitals do not exist in Germany.

${ }^{16}$ Stolle et al. (2010) also provide some empirical evidence that the German hospital diagnosis statistics underestimate the alcohol-related hospitalizations of children and adolescents.

${ }^{17}$ However, when we express the reform's effect as percentage changes in the overall level of alcoholrelated hospitalizations, we might estimate these percentage changes consistently if the share of misclassified hospitalizations is constant.
} 
To define alcohol-related hospitalizations (ARH), we follow Wicki and Gmel (2011) in relying on the codes F10 ("Mental and behavioral disorders due to alcohol use") and T51 ("Toxic effect of alcohol") of the 3-digital ICD-10 classification ("International Statistical Classification of Diseases and Related Health Problems") constructed by the WHO. ${ }^{18}$

We aggregate the number of alcohol-related hospitalizations by month of admission and inpatient's county of residence. Hence, we construct a balanced panel of the 402 German counties as of January 2011 (44 of them are in Baden-Württemberg) covering a period of 60 months. This gives rise to 24,120 county-month observations. In order to make the ARH numbers comparable across counties with different population sizes, we calculate hospitalization rates per 100,000 inhabitants. ${ }^{19}$ For this purpose, we combine the hospital diagnosis statistics with county population data from the German Federal Statistical Office. In addition, we map further information at the county level into the hospital diagnosis statistics for the construction of control variables: the county's population density, the general unemployment rate, the youth unemployment rate (defined as unemployment rate among individuals below 25), and the county's GDP. ${ }^{20}$

In our analysis, we study the effect of the reform on alcohol-related hospitalization rates for the entire population and for specific age groups. We focus on young people as there are several reasons to assume that the reform impacts young individuals in particular (see section III). We study potential effects of the ban for different age groups of young people divided into five-year age brackets: ages $15-19,20-24$, and $25-29 .^{21}$ We also analyze all individuals aged 30 and older. In Section A, we further differentiate the age groups.

Figure 3 displays average monthly alcohol-related hospitalizations per 100,000 inhabitants of the same age and gender in 2009, the year prior to the ban. One can see that there are not many alcohol-related hospitalizations prior to age 13. Moreover, among individuals aged 14 and younger, gender differences are not large (ARH rates are slightly higher among females aged 13 and 14). Starting at 15, male ARH rates always exceed female ARH rates and are about twice as high. ${ }^{22}$ Among males, ARH rates peak at the age of 16, the minimum legal drinking age, then decrease, and remain at a relatively constant level after age 20. Similarly, female ARH rates peak at 15/16 years of age and level off after age 20 .

\footnotetext{
${ }^{18}$ In section VII, we show that our results are robust to only using the code F10, which accounts for about 98 percent of the cases that we classify as alcohol-related hospitalizations.

${ }^{19}$ We reweight the number of alcohol-related hospitalizations by the inverse of 0.7 , in order to take into account that we are only provided with a 70 percent random sample.

${ }^{20}$ These annual data are publicly available from https://www.regionalstatistik.de/genesis/ online/data.

${ }^{21}$ These age brackets are also used in publications of the Federal Statistical Office on ARH among the youth.

${ }^{22}$ The magnitude of this gender difference is in line with findings from self-reported binge drinking rates (BZgA 2012).
} 
In addition to the German hospital diagnosis statistics, we use data from one large hospital outside of Baden-Württemberg to provide additional descriptive evidence. ${ }^{23}$ This data set comprises more than 14,000 alcohol-related hospital admissions for the years 2007-2013. Consistent with the national statistics, these data show an increase in the number of alcohol-related hospitalizations over time and significantly higher admission rates among men than among women. The main advantage of these hospital data is detailed information on the timing of admissions and releases (e.g., hours and day of admission), the number of procedures carried out by the hospital, the number of additional diagnoses, and whether the patient was operated on, admitted to intensive care, or given artificial respiration. This hospital data shows that the majority of alcohol-related hospital admissions among adolescents and young adults occur in the late evening and at night (Figure 2) and on weekends (Figure A.1 in the Appendix).

\section{Empirical strategy}

We estimate basic difference-in-differences (DiD) models and regression difference-indifferences models with various control variables in order to inspect the effect of the late-night alcohol sales ban on alcohol-related hospitalization rates. The basic DiD model takes on the form:

$$
A R H_{c s t}=\alpha_{0}+\beta \cdot \operatorname{ban}_{s t}+\alpha_{1} \cdot \text { post }_{t}+\alpha_{2} \cdot B a W u_{s}+\varepsilon_{c s t}
$$

where $A R H_{\text {cst }}$ refers to the alcohol-related hospitalization rate in county $c$ in state $s$ in month $t$. $b a n_{s t}$ denotes our prime variable of interest, a binary variable that equals one if the late-night alcohol sales ban is in force in state $s$ in month $t$ and zero otherwise (i.e., the interaction term of post $_{t}$ and $\left.B a W u_{s}\right)$. The other two regressors in the basic DiD model are binary variables for the post-treatment period $\left(\right.$ post $\left._{t}\right)$ and the treatment state Baden-Württemberg $\left(B a W u_{s}\right) . \varepsilon_{c s t}$ is the error term, which might be correlated within states. Therefore, we cluster standard errors on the state level. ${ }^{24}$ We estimate equation (1) for hospitalization rates in different age groups.

In the regression difference-in-differences models with various control variables, we

\footnotetext{
${ }^{23}$ Due to data confidentiality we are not allowed to provide the name of the hospital or the state in which it is located.

${ }^{24}$ There is a discussion in the literature on the appropriateness of clustered standard errors when the number of clusters is small (Donald and Lang 2007). In the robustness section, we also report wild cluster bootstrap procedures (Cameron et al. 2008). Additionally, we perform analyses using panel-corrected standard errors.
} 
refine and supplement equation (1) and estimate equations of the following form:

$$
A R H_{c s t}=\alpha_{0}+\beta \cdot \operatorname{ban}_{s t}+\gamma_{c}+\delta_{t}+X_{c s t}^{\prime} \lambda+\kappa_{s, \text { season }}+\varepsilon_{c s t} .
$$

Instead of the $B a W u_{s}$ indicator in the basic DiD model, we include a set of county fixed effects, $\gamma_{c}$, accounting for time-invariant differences in the level of alcohol-related hospitalizations between the counties (and, hence, also between the German states). We replace the indicator for the post-treatment period, post $t_{t}$, with a maximum set of time (month-year) dummy variables, $\delta_{t}$, controlling for time shocks that commonly influence alcohol-related hospitalizations in the German states (e.g., federal drunk driving laws). ${ }^{25}$ $X_{c s t}$ denotes a set of time-varying control variables at the county and state levels. It includes the state's share in total German GDP, the county's general unemployment rate, and the county's youth unemployment rate as measures of the economic situation. Furthermore, in order to monitor changes in the population composition, $X_{c s t}$ includes the population density of the county and the number of individuals of the analyzed age in the county as a share of the its total population. Additionally, $X_{c s t}$ includes a set of dummy variables for different shopping hour regimes to address the issue of changes in the law on opening hours of supermarkets (see section III). ${ }^{26} \kappa_{s, \text { season }}$ is a set of season-specific state dummies capturing seasonal differences between states. ${ }^{27}$ There may be seasonal differences in $\mathrm{ARH}$ rates between states due to variations in celebrations. For example, Baden-Württemberg is famous for its Carnival celebration, which takes place in February.

In section VI we start with the basic DiD models and then gradually incorporate the control variables from equation (2). We estimate equations (1) and (2) by weighted least squares, where the weights are given by the county's population of the analyzed age in order to obtain the accurate overall effect for Baden-Württemberg. Draca et al. (2011) and Kelly and Rasul (2014) apply similar weighting procedures on their aggregated data.

\section{Main results}

\section{A. Basic difference-in-differences results}

Table 1 reports the results from basic difference-in-differences models. The first panel of the table shows the results for all age groups combined. The lower panels display the

\footnotetext{
${ }^{25}$ Since we replace the post-treatment period and the treatment state indicators with time and county fixed effects, our regression DiD can also be regarded as a two-way fixed effects regression.

${ }^{26}$ More specifically, this set includes three indicator variables: (i) shopping is allowed around the clock except Sundays; (ii) shopping is allowed around the clock except Saturdays and Sundays; and (iii) shopping is allowed until 10pm during the week and on Saturdays. Shopping allowed until 8pm during the week and on Saturdays (i.e., the federal regulation prior to 2007) constitutes the reference category.

${ }^{27}$ Seasons are defined as January-March, April-June, July-September, and October-December.
} 
results of separate models by age groups (ages 15-19, 20-24, 25-29, 30 and older), since risky drinking behavior varies considerably by age and the impact of the law is more likely to affect young people. Figures in the first column of the table display averages in the monthly number of alcohol-related hospitalizations per 100,000 inhabitants prior to the implementation of the ban on March 1, 2010. Figures in the second column show the corresponding averages for the period March 2010 to December 2011. The basic differencein-differences approach estimates the impact of the law by comparing the difference in the hospitalization rates between Baden-Württemberg (treatment) and all other German states (control) before and after the introduction of the late-night alcohol sales ban.

The figures in the first row show that in Baden-Württemberg the hospitalization rate for all age groups combined remain very stable over time, with 35 monthly alcohol-related hospitalizations per 100,000 inhabitants before and 35.14 after the implementation of the alcohol ban. In contrast, the rate of alcohol-related hospitalizations increases by 0.39 in the other states, resulting in an estimated overall reduction of 0.25 alcohol-related hospitalizations per 100,000 inhabitants due to the late-night alcohol ban. The reduction of 0.25 hospitalizations corresponds to an overall decrease in alcohol-related hospitalizations by 0.7 percent $(=0.25 /(0.25+35.14)){ }^{28}$

The separate estimates for the four different age groups show striking results. First, the alcohol-related hospitalization rate of adolescents (ages 15-19) decreases by seven percent due to the ban. Similarly, for young adults (ages 20-24) there is a drop in alcohol-related hospitalizations of around six percent. The effect for adolescents and young adults is driven by a considerably smaller increase in the ARH rate in the treatment state compared to the control states. In contrast, for individuals aged 25 to 29, the increase in the ARH rate in the treatment state is slightly larger than the increase in the comparison group. The last panel indicates that the reform involved also no reduction in alcohol-related hospitalizations for individuals aged 30 and older. This finding suggests that the overall reform effect found in Panel A is basically driven by young individuals.

\section{B. Regression difference-in-differences}

Taking the basic, unconditional DiD estimates from Table 1 as a starting point, Table 2 reports estimated coefficients and standard errors from several difference-in-differences regressions. Each coefficient represents an estimate from a separate regression, with standard errors clustered on the state level. Column 1 replicates the results from the basic difference-in-differences models. The other columns gradually include further control variables as indicated by the column headings.

\footnotetext{
${ }^{28}$ Without the reform, we estimate that there would be $35.39(=0.25+35.14)$ hospitalizations per month.
} 
One can see that two of the five point estimates in the first column are significantly different from zero at conventional significance levels. The second column reports differencein-differences estimates, including fixed effects for the 402 counties and the 60 months. The estimates in the second column are very similar in magnitude to the basic difference-indifferences estimates. In the third column, we also add time-varying county characteristics (general and youth unemployment rate, county's share in total German GDP, county's population density, share of individuals of the analyzed age, dummy variables for different shopping hour regimes). The inclusion of these additional explanatory variables changes the estimated coefficients slightly. For adolescents (aged 15-19) and young adults (aged 20-24) as well as for the overall population, the impact of the ban becomes somewhat stronger (more negative). As a result of the larger effect (and a narrower confidence interval), the overall decline in hospitalizations (Panel A) is now significant at at the one percent level.

The last column adds state-specific seasonal dummy variables to control for potential differential seasonal influences across states. This is our preferred specification. The inclusion of these additional control variables shows relatively little effect on the estimated coefficients for young people aged 15-19 and 20-24. The estimated coefficients of -3.35 and -1.98 for these two age groups suggest that the alcohol-related hospitalizations among adolescents and young adults decrease by around seven percent. The effects for those aged 25-29 as well as aged 30 and older are not significant in any of the specifications in this table.

Overall, the estimates in Table 2 point to two important findings. First, the results suggest that the late-night alcohol ban significantly reduces alcohol-related hospitalizations among adolescents and young adults. Second, alcohol-related hospitalization rates among adults older than 25 do not change significantly with the introduction of the latenight alcohol ban. The significant overall reform effect is basically driven by adolescents and young adults, as their alcohol-related hospitalizations decrease by around seven percent. Is this a small or rather large reduction? While we are not aware of other papers examining interventions to curb alcohol-related hospitalizations in Germany, a comparison of our results with those of Hwang et al. (2005) might be informative. The authors study the relationship between neighborhood income levels (quintiles) and alcohol-related hospitalizations among residents of Toronto. ${ }^{29}$ Among men aged 20-39, alcohol-related hospitalizations are found to be 13 percent higher in the lowest compared to the highest income quintile. As such, a seven percent reduction is roughly equivalent to half the difference in alcohol-related hospitalization rates between the poorest and the richest

\footnotetext{
${ }^{29} \mathrm{~A}$ comparison with this study is interesting, since, similar to Germany, Canada has a universal health insurance and hospitalizations are registered in a single administrative data set.
} 
neighborhoods in their study.

In order to assess the magnitude of the effects further, we can also compare the reduction brought about by the ban with changes in ARH rates over time. For instance, among adolescents, ARH rates in Baden-Württemberg increased from 305 hospitalizations in 2003 to 577 per 100,000 inhabitants in 2009. This corresponds to an average annual increase of about 45 alcohol-related hospitalizations per 100,000 inhabitants prior to the implementation of the ban. According to our point estimate for adolescents, the ban reduces ARH by around 40 hospitalizations per 100,000 inhabitants on average per year. Hence, the ban is estimated to reduce ARH rates by about the same magnitude as the average annual secular increase in ARH in the pre-ban period. ${ }^{30}$ These comparisons highlight that the impact of the ban can be interpreted as a sizable effect. However, the effect size is considerably smaller than the reduction in ARH rates due to the joint effects of a general ban on alcohol sales in gas stations and video stores and a ban on late-night alcohol sales reported by Wicki and Gmel (2011) for Switzerland.

Why is it that mainly adolescents and young adults are affected by the late-night alcohol ban, but those aged 30 and older are not? One explanation might be differences in the frequency and location of alcohol consumption, or differences in purchasing and storing behavior. For example, those aged 30 and older might be more likely to consume alcohol with dinner or in the evening at home rather than outside the home. As a result, they might be less likely to be affected by the late-night off-premise alcohol sales ban as they are more likely to buy alcohol ahead of time and store it for later consumption. Supporting descriptive evidence for this explanation comes from the representative Epidemiological Addiction Survey. In 2006, this cross-sectional survey interviewed nearly 8,000 respondents aged 18-65 in Germany about their frequency of alcohol consumption during the last 12 months in certain situations such as (a) in the evening at home, (b) with lunch or dinner at home; (c) at parties, celebrations, or festivities. Answers to these questions suggest that young people aged 18-24 are considerably less likely to consume alcohol at home compared to those aged 30 and older. In stark contrast, they are more likely to drink alcohol at parties or festivities. For example, 28 percent of those aged 18-24 report that they consume alcohol one to two times per week at parties, celebrations, or festivities compared to only three percent among those aged 30 and older. These figures suggest that young adults are considerably less likely to consume alcohol at home, and more likely to drink outside the home, where the ban is likely to have more of an effect.

\footnotetext{
${ }^{30}$ Similarly, for young adults in Baden-Württemberg aged 20-24, we observe an average annual increase of about 19 ARH per 100,000 people between 2003-2009. Again, this roughly corresponds to 24 fewer annual alcohol-related hospitalizations per 100,000 people due to the ban.
} 


\section{Robustness checks}

This section presents various robustness tests. The first part investigates the sensitivity of the results to different control groups, and the second part provides robustness tests with respect to various sample restrictions, estimation issues, as well as different control variables. The third part discusses further robustness issues.

\section{A. Different control groups}

The key assumption for our identification strategy is that in the absence of the ban, alcohol-related hospitalization rates in Baden-Württemberg (the treatment state) would follow the same trend as in the control group. We cannot test this assumption directly, but an inspection of the trends before the ban came into effect might yield valuable insights regarding the plausibility of this identification assumption. Figure 4 displays the trends in ARH rates for Baden-Württemberg and the rest of Germany, separately for the five age groups. For the overall population (Panel a) as well as for individuals aged 30 and older (Panel e), the two lines follow very similar trends, with Baden-Württemberg exhibiting slightly lower ARH rates than the rest of Germany. A strong seasonal pattern in ARH rates is apparent, with higher rates in summer and lower rates in winter. The graphical inspections in Panels a) and e) in Figure 4 support the findings from the regression analysis that there is no effect of the ban on ARH rates in the overall population and among those aged 30 and older. For adolescents (Panel b) the two lines follow a somewhat similar trend, but they are clearly not as close as those in Panels a) and e). While for adolescents the ARH rates in Baden-Württemberg annually peak in January/February, for the rest of Germany the highest annual ARH rates can be mainly found in May/June. Note that in the regression analysis, these seasonal differences in ARH rates should be mitigated by the inclusion of state-specific seasonal indicator variables. For individuals aged 20-24 (Panel c) and aged 25-29 (Panel d), the trends in ARH rates seem somewhat more similar than the trends in ARH rates for adolescents in the treatment and control groups. ${ }^{31}$ The ban's effect for individuals aged 20-24 can also be seen in this graph: before the ban, the line for Baden-Württemberg was mostly above the line for the rest of Germany, whereas after the introduction of the ban, this was basically the reverse.

In summary, the graphs in Figure 4 show that the trends in ARH rates are fairly similar between Baden-Württemberg and the rest of Germany. However, particularly for the age groups that show significant decreases in ARH rates after the introduction of

\footnotetext{
${ }^{31}$ In Panel c), the trends are quite different in the year 2007. We exclude this year in a robustness check. In another robustness exercise, we exclude January and February 2010 as these months seem to exhibit particular peaks in some of the graphs.
} 
the alcohol ban, the pre-treatment trends look slightly less similar. Some of the trend differences will be mitigated by our control variables. Nevertheless, in order to investigate whether our estimates are sensitive to the selection of the control group, we also work with different control groups.

The first alternative control group comprises only counties in western Germany, and the second control group includes only counties in the southern German states of Bavaria and Hesse. Bavaria and Hesse are most similar to Baden-Württemberg in terms of location, the political orientation of the government during the period under analysis (centerright), and economic performance (e.g., GDP per capita and unemployment rate). They also have similar overall ARH rates before the ban. The last control group constitutes a synthetic control group. The counties in the synthetic control group are reweighted such that the ARH rates follow exactly the same trend as the treatment counties before the introduction of the ban. This means that the fourth control group exhibits the same average hospitalization rate as in Baden-Württemberg in every month in the pre-ban period January 2007 through February 2010. We construct this synthetic control group applying the matching/reweighting technique "entropy balancing" (Hainmueller 2012). We rely on a separate synthetic control group for every age group.

Figure A.2 in the Appendix presents the trends in ARH rates for Baden-Württemberg and the alternative control groups separately for the five age groups. In general, none of the "natural" control groups (i.e., western Germany, Hesse and Bavaria only) seems superior to our main control group with respect to the similarity in pre-treatment trends. However, it is also evident from this figure that for each age group-by construction-the synthetic control group follows exactly the same trend before the treatment as in BadenWürttemberg. As another way to inspect the similarities in pre-treatment trends, we also compute correlations $(\rho)$ of the pre-treatment $\mathrm{ARH}$ rates in Baden-Württemberg with the ARH rates in the various control groups. All correlation coefficients are statistically significant from zero at the one percent level. In general, the correlation in pre-treatment $\mathrm{ARH}$ rates is highest for the overall sample and for the sample of individuals aged 30 and older $(\rho=0.9)$, while for the younger age groups the correlation is lower (e.g. $\rho$ is between 0.67 and 0.77 for adolescents and between 0.54 and 0.57 for young adults). By construction the correlation is 1.00 for the synthetic control group for all age groups.

Table 3 reports the difference-in-differences estimates for the four control groups. Overall, the results confirm the findings from the main specification. No matter which control group is used, the ban is estimated to reduce ARH rates for adolescents and young adults, but not for older adults. The table indicates that our main results based on all German states are rather conservative, as all alternative estimates for young people are larger in magnitude. When relying on Hesse and Bavaria (southern states) as a comparison, the 
ban is estimated to reduce alcohol-related hospitalizations among adolescents and young adults by 10-11 percent, compared to seven percent when using all states or only western German states. ${ }^{32}$ Similarly, the DiD estimates from the synthetic control group suggest a reduction of eight percent for young people aged 15-24.

\section{B. Sample restrictions, estimation issues, and additional controls}

The first set of robustness exercises in this subsection consists of applying different sample restrictions (temporal, regional, individual). The second set deals with various estimation issues, and the third set includes additional control variables. Table 4 reports the results for these additional robustness checks.

First, we restrict the period of analysis to the years 2008-2011. In this period, there were no changes in shopping hours in any state. Second, we exclude January and February 2010 from the sample as these months showed some peculiarities in the graphical inspections (see Figure 4). Next, we perform regional sample restrictions and exclude counties in the treatment state that neighbor on other German states (Bavaria, Hesse, Rhineland-Palatinate) in order to examine potential effects of cross-border shopping (Table 4, column 3). ${ }^{33}$ Fourth, in order to check the sensitivity of our estimates to outliers in the treatment group, we exclude the five percent of the treated counties with the highest increase in alcohol-related hospitalizations and the five percent with the highest decrease from before to after the ban. Fifth, we restrict the sample on the individual level and only use the diagnosis F10 ("Mental and behavioral disorders due to alcohol use") in order to construct ARH rates, as press releases and government reports on youth binge drinking often only consider hospitalizations with this diagnosis. Sixth, we only consider individuals who were released from hospital in the same year that they were admitted. This is done in order to eliminate any potential bias from the fact that we do not observe cases in our data that were hospitalized in or before 2011 but released after $2011 .^{34}$

The next set of robustness tests relates to various estimation issues. A weak point of the difference-in-differences approach in general is that the validity of the identification assumption depends on the outcome's scale of measurement (see e.g. Lechner 2010). Therefore, in column 7 , we analyze the sensitivity of our results to a transformation of

\footnotetext{
${ }^{32}$ When relying on only Hesse and Bavaria as the control group, the effect on adolescents becomes insignificant. This imprecision is not surprising given that-also for this specification with three states -standard errors are clustered on the state level. When we cluster on the county level or on the state-year level, the coefficient becomes statistically significant at the five percent level.

${ }^{33} \mathrm{We}$ also investigated whether the ban affects ARH rates in counties that neighbor BadenWürttemberg, where young people may live closer to off-premise outlets in Baden-Württemberg than to outlets in their own state. We found no evidence for significant spillover effects of the ban.

${ }^{34}$ This restriction mainly drops cases that were admitted in December of one year and released in January of the following year.
} 
the outcome variable by taking the logarithm of the ARH rate as the dependent variable. This transformation has the advantage that the estimated coefficients can be interpreted as approximate percentage changes. Column 8 in Table 4 applies an alternative method to estimate equation (2), the Tobit model, as the ARH rates are censored at zero. Column 9 uses states as the unit of analysis, as the ban was introduced at the state level. However, this specification does not allow us to include information on the county level. The next column of Table 4 presents results from a placebo regression by pretending that the ban in Baden-Württemberg took place one year earlier (i.e., on 1 March, 2009). For this purpose, we estimate equation (2) with two modifications: we construct a pseudo-treatment indicator using the placebo policy change and delete those time periods when the actual ban was in effect from the sample, i.e., we drop the months from March 2010 through December 2011.

The third set of robustness checks deals with the inclusion of further control variables. First, we include state-specific linear time trends as our estimates might be confounded by natural time trends in ARH rates, which might differ between states (column 11 in Table 4). Similarly, in column 12 we include linear time trends for each of the 402 counties. The next specification replaces the state-specific seasonal dummies by state-specific month dummies, i.e., by interactions of the 16 states with the 12 months. This replacement might be more accurate, but it increases the number of control variables considerably. The final column in Table 4 investigates whether the findings are robust to the inclusion of an indicator variable capturing the extension of the general legal bar hours in BadenWürttemberg in January 2010 (see section III). ${ }^{35}$

The results in Table 4 show that the estimates from the main specification are strikingly robust: among those aged 15-19 and 20-24, the decreases in ARH rates due to the ban are significant in all specifications (except of the placebo regression). In contrast, among those aged 25-29 as well as among those aged 30 and older, the ban only exhibits a significant reduction of $\mathrm{ARH}$ rates in two out of 28 regressions. For individuals aged 15-19, the effect size varies between 5.1 percent and nine percent, whereas for young adults, the effect size basically varies between 4.9 percent and ten percent depending on the specification used. Moreover, the results of the placebo regressions in column ten of Table 4 show that the placebo policy change in March 2009 has no significant effects on ARH rates. These findings add further credibility to the identification assumption and indicate that the estimated effects of the actual ban are unlikely to be driven by volatility in the ARH rates over time.

\footnotetext{
${ }^{35}$ This indicator variable takes on the value one for all observations in Baden-Württemberg starting in January 2010 and is zero otherwise. Hence, this indicator variable differs from our main treatment indicator only with respect to the classification of January and February 2010.
} 
One notable finding in Table 4 is the point estimate on the effect of the late-night alcohol ban among those aged 20-24 in column 14, suggesting a reduction in alcoholrelated hospitalizations of around 20 percent. This specification includes an additional dummy variable that captures the effect of the new law extending bar hours in BadenWürttemberg starting in January 2010. ${ }^{36}$ To investigate this issue further, we also study the impact of an extension of bar hours that took place in Bavaria on January 1, 2005. While Baden-Württemberg extended bar hours by one hour during the week, the extension was more substantial in Bavaria: closing time was extended from 2am to 5 am on weekdays and from 3am to 5am on weekends. This institutional change helps us to shed additional light on whether ARH rates are likely to be influenced by the extension of bar hours. Table A.1 in the Appendix reports the estimated effects on extending bar hours in Bavaria for the years 2003-2005. ${ }^{37}$ During this period, no other state in Germany changed the bar hours. Similar to Table 2, we report DiD estimates from four different specifications (columns 1-4), starting with the basic DiD results in column 1. In addition, column 5 in Table A.1 reports the estimated coefficients when also controlling for state-specific linear time trends.

Strikingly, none of the estimated coefficients in Table A.1 on extending the legal bar hours in Bavaria is of sizable magnitude or statistically significant for adolescents and young adults. ${ }^{38}$ This suggests that the extension of the bar hours in Bavaria had no impact on alcohol-related hospitalizations among adolescents and young adults. Among those aged 25 and older, the extension of bar hours in Bavaria seems to have reduced ARH by around 4-8 percent (columns 1-4 in Table A.1). However, these estimates reverse their sign, drop to near zero, and are no longer statistically significant once we also control for state-specific linear time trends (column 5).

These results for Bavaria on a more substantive extension of bar hours suggest that we should not trust the very large effect of the extension of the bar hours in BadenWürttemberg and, hence, also not the large effect of the late-night ban on alcohol sales in column 14 of Table 4. It also seems implausible that the bar hour extension in BadenWürttemberg should have such a large effect for individuals in the 20-24 age group, while it affects neither the 15-19 nor the 25-29 age group. Further, it is important to point out that

\footnotetext{
${ }^{36}$ The estimated coefficient on the dummy variable capturing the change in the extension of the bar hours is 5.69, and is precisely estimated at the one percent significance level. However, none of the corresponding estimates in the other age groups suggests a large and significant increase in ARH due to the extension in the legal bar hours in Baden-Württemberg. The other effect sizes are 0.26 (overall), -0.61 (ages 15-19), 0.06 (ages 25-29), and -0.19 (age 30 and older).

${ }^{37}$ The sample for this specification is based on 388 counties covering the years 2003-2005, i.e., 13,968 county-month observations. We had to discard observations from Saxony-Anhalt due to a reform that redrew county lines within the state.

${ }^{38}$ These findings are robust to various sensitivity checks with respect to the sample period and the inclusion of additional control variables.
} 
municipalities did not have to follow the state regulation strictly: they were still allowed to pass municipal laws extending or reducing the bar hours. Hence, changes in bar hours were less binding than the late-night ban on off-premise alcohol sales. Moreover, as the effect of the extended bar hours is identified by only two months, January and February 2010 , it cannot be ruled out that the effect is driven by time-series volatility and/or by specific events that only occurred in January/February 2010 in Baden-Württemberg. ${ }^{39}$ For all these reasons, specification 14 of Table 4 is not our preferred specification. Our preferred specification provides a more conservative-but in our view- more reliable effect size of the late-night alcohol sales ban.

Finally, as there is a discussion in the literature on the appropriateness of clustered standard errors when the number of clusters is small (Donald and Lang 2007), we also apply wild cluster bootstrap procedures (Cameron et al. 2008). Table A.2 in the Appendix displays $p$-values based on clustered standard errors and $p$-values based on wild cluster bootstrap procedures for our preferred specification. The table shows that the conclusions do not change when applying wild cluster bootstrap procedures as the $p$-values are very similar to $p$-values based on conventional clustering. Further, the results are also robust when estimating panel-corrected standard errors with and without first-order autocorrelation (columns 4-5 in Table A.2).

\section{Discussion}

A potential concern with the present findings is reverse causation bias, if, for example, Baden-Württemberg had decided to implement the law as a result of a short-term increase in alcohol-related problems or alcohol-related hospital admissions prior to the ban. While we cannot completely rule out this possibility, Figure 4 shows that there were no considerable differences in alcohol-related admissions in Baden-Württemberg prior to the ban compared to other states. Additionally, in Table 3 we only consider the states Bavaria and Hesse for the control group. This comparison is appealing since these three states are most similar in terms of economic performance and political orientation of the government (center-right). Hence, reverse causality is likely to be less of an issue in these estimates as there are no obvious reasons why the conservative government in Baden-Württemberg decided to implement the late-night alcohol ban while those in Bavaria and Hesse did not. It is also important to point out that the ban was not implemented as a result of a state referendum. Moreover, the governing party in Baden-Württemberg, the Christian Democratic Union (CDU), which was mainly responsible for enacting the law, did not

\footnotetext{
${ }^{39}$ This concern is corroborated by the fact that we also obtain a significant effect of the ban for children younger than 15 in this specification (results not shown). Children of this age should not be affected by the extension of bar hours as they are forbidden by law from being in bars at that time of day.
} 
mention a late-night off-premise alcohol sales ban in its electoral program for the previous state election in 2006 (CDU Baden-Württemberg 2006). Overall, this suggests that reverse causality is unlikely to be major concern: the people of Baden-Württemberg could not vote on the ban through a referendum. Also, they could not influence it indirectly by voting for the CDU because at the time of the election an alcohol ban was not part of the party's electoral program.

Another potential problem with the present estimates might be that the late-night alcohol sales ban affects alcohol-related hospitalizations but does not actually impact on people's patterns of alcohol consumption. For example, it might be that young people in the treatment area are less likely to be brought to the hospital after the implementation of the ban because they binge drink more at home. To shed some light on this possibility, we complement the analysis with descriptive evidence from a representative survey conducted by the Federal Center for Health Education (Bundeszentrale für gesundheitliche Aufklärung, BZgA). Between June and August 2010, the BZgA interviewed young people in Germany, asking whether they had (binge) drunk alcohol in the last 30 days. Respondents were also asked: "If you drink larger quantities of alcohol, and by larger quantities I mean five drinks or more, where do you mainly drink?" Figure A.3 shows that-shortly after the introduction of the late-night alcohol sales ban-only six percent of heavy alcohol consumers aged 15-19 who live in Baden-Württemberg report binge drinking at home, compared to around eight percent in the comparison group. Among those aged 20-24, only around one in ten heavy alcohol consumers reports binge drinking mainly at home, with no considerable differences between individuals in the treatment and comparison states. The lower proportion of adolescents binge drinking at home might be due to stronger supervision by parents at home. We interpret these figures as suggestive evidence that it is rather unlikely that the late-night ban makes young people in Baden-Württemberg more likely to drink excessively at home. ${ }^{40}$

\section{Further results}

The first part of this section investigates whether the effect of the ban differs by individual characteristics (e.g., gender, smaller age ranges). Subsection B analyzes the (short-run) development of the ban's impact over time, subsection C studies potential effects of the ban on the length of stay for alcohol-related hospitalizations, while subsection D examines effects on illicit drug-related hospitalizations, hospitalizations due to diagnoses related to violent assaults, and placebo outcomes.

\footnotetext{
${ }^{40}$ Note that we cannot estimate DiD estimates for the outcome variable "binge drinking at home" since the BZgA only asked this information after the implementation of the ban.
} 


\section{A. Heterogeneity of the treatment effect}

There are considerable differences in alcohol consumption, binge drinking behavior, and $\mathrm{ARH}$ rates between men and women. In order to analyze whether the ban affects men and women differentially, we estimate separate models by gender. Table 5 reports the results using the main specification (as in the last column of Table 2). The table shows that the ban reduces ARH for female and male adolescents and young adults, while the reduction is stronger among males. For neither men nor women do we find significant negative effects of the ban for the other age groups. ${ }^{41}$

In Figure 5, we break up the specific age groups of young people used in the previous sections in order to investigate whether the grouping hides differences in the ban's effect within age groups. More specifically, we estimate the ban's effect and the corresponding 95-percent confidence interval for each age separately. Figure 5 shows that the ban's effect is estimated to reduce ARH rates for nearly all ages between 13 and 25. However, the reduction is only statistically significant for the ages $15,17-18$ and 22-24.

Outside this age ranges, we do not find that the ban lead to any significant reductions in young people's ARH rates. This gives us confidence that the age categories used in the previous section cover the relevant ages quite well. We find the largest reduction in ARH rates for individuals aged 18 -that is, when young people reach adulthood and can legally consume or purchase hard liquor and remain in bars and clubs until closing time. Figure A.4 in the Appendix displays the ban's effect for further age groups. It shows that breaking the age group of individuals aged 30 and older into 10-year age groups confirms that the ban has no effect on ARH rates of older individuals.

\section{B. Evolution of the treatment effect}

This subsection investigates how the effect of the late-night alcohol ban evolves over time. Analyzing the dynamic of the treatment effect is important: it might be that the impact of the ban eventually converges to zero due to improved avoidance strategies on both the demand side for alcohol and the supply side. For instance, owners of gas stations might open restaurants or bars nearby to legally avoid the late-night off-premise alcohol ban. On the demand side, individuals might improve their pre-stocking opportunities (e.g., by finding hideouts) or start their pre-drinking behavior at even earlier hours. Also, a black market for off-premise sales of alcoholic beverages might take some time to develop. However, it is difficult to distinguish consequences of improved avoidance strategies from differential seasonal effects of the ban. For instance, the ban might be more effective in

\footnotetext{
${ }^{41}$ Surprisingly, the late-night ban seems to increase the number of alcohol-related hospital admissions among women aged 25-29, with the point estimate being significant at the five percent level. However, this effect is not robust once we also control for state-specific or county-specific linear time trends.
} 
summertime, when people are more likely to drink outside. The ban might also have differential effects during school vacations (when every day is like a weekend).

Table 6 presents how the treatment effect evolves over time. The underlying regression equation resembles the main specification, i.e., equation (2), with the difference that, instead of a single treatment indicator combining the 22 months from March 2010 to December 2011, there are eleven mutually exclusive treatment indicators, each depicting the treatment effect for two subsequent months. ${ }^{42}$ Furthermore, we include indicators for a few sets of months prior to the ban (i.e., interactions between the treatment state and the months November/December 2009 and January/February 2010). This can be seen as a kind of placebo test (similar to the estimates in column 10 in Table 4) and-given the volatility in our time series-the placebo treatments facilitate to assess whether the size of the actual treatment effects is exceptionally large compared to volatility-induced differences in the pre-treatment period. ${ }^{43}$ Additionally, for the specification in Table 6 , we replace the state-specific seasonal dummies from equation (2) with state-specific month dummies (see specification 13 in Table 4) as the treatment effects are estimated for sets of two months.

The table shows that for both adolescents and young adults, the ban's overall effect is not driven by single months (and, hence, not by single events) since we obtain negative point estimates for most of the post-treatment period. For instance, for adolescents (Panel B), ten of the eleven bimonthly treatment indicators show a negative sign (six of them are statistically different from zero). For this age group, we obtain the largest treatment effects in the months following the implementation and also at the very end of our observation period (September-December 2011). Hence, the ban's effect does not seem to fade out over time. ${ }^{44}$ Further, there is no evidence that in this age group the ban is more effective in summer or winter. This is different for young adults (Panel C). Here, we find the largest effects of the ban in the warmer months May to August in both years, whereas in November/December the ban does not seem to be effective in reducing alcohol-related hospitalizations. Therefore, we do not interpret the two positive coefficients at the end of our observation period as evidence that the ban's effect is fading out over time for this

\footnotetext{
${ }^{42}$ Similar pictures emerge when we group more months together, e.g., three, four or six, and when we look at each month separately. The more months we group together, the less volatile the point estimates become. Grouping two months together seems to be the best trade-off between reducing volatility and being able to analyze the evolution of the treatment effect in a detailed manner.

${ }^{43}$ The eleven treatment indicators in Table 6 do not change notably when we exclude the placebo treatments.

${ }^{44}$ In an alternative specification to investigate the evolution of the treatment effect, we complemented equation (2) by a linear post-treatment time trend for the treatment state (i.e., an interaction term between the treatment effect and the number of months since the implementation of the ban). This linear post-treatment time trend was small and insignificant for adolescents, supporting the notion that the effect is not declining over time.
} 
age group.

Why is it that the effect of the ban shows a rather cyclical pattern for young adults but not for adolescents? One answer may lie in differing ARH patterns of these two age groups over the year. Figure 4 shows that in the pre-treatment period in Baden-Württemberg, the ARH rates annually peak in May-September for young adults, while for adolescents, a clear seasonal pattern is not observable. It seems that for young adults the ban is most effective in the months when most excessive alcohol consumption usually takes place.

Table 6 also provides some indication that the ban might affect individuals in the age range of 25 to 29 as well. For this age group, strong and significant reductions in ARH rates can be observed for July/August and September/October 2010. However, for March/April 2010, the ban is estimated to significantly increase ARH rates. This is consistent with the graphical evidence in Figure 4. The two opposing effects roughly cancel each other out and, therefore, we do not find an overall effect of the ban on ARH rates for this age group. A potential explanation might be defiance: individuals in this age group might react to the implementation of the unpopular late-night ban by increasing their excessive alcohol consumption initially, but then stop this defiant behavior later. Another explanation is that the findings might be driven by time series volatility as the monthly ARH rates of young people are rather volatile (see Figure 4).

To further assess whether our results might be driven by time series volatility, we look at the effects of the placebo treatment indicators for November/December 2009 and January/February 2010. Taking all age groups together, nine out of the ten placebo treatment effects are small and statistically insignificant, suggesting that our results are not driven simply by volatility in the data. However, for the age group 20-24, the effect for January/February 2010 is large, statistically significant, and positive. This point estimate is not very surprising given the spike in ARH rates in January/February 2010 (see Panel $\mathrm{C}$ of Figure 4) and the strong effect of the bar-hour reform in the previous section that was only identified by January and February 2010.

Does this constitute a problem for our identification strategy? We do not think so. First, note that the effect is not negative. If the effect were negative we might have suspected that the decrease in the $\mathrm{ARH}$ rates in the treatment state already started before the ban and, hence, might have been unrelated to the ban. Further, the ban cannot be the result of the increase in ARH rates among young adults in the first months of 2010, as the law was already passed long before. Second, note that the increase in ARH in January/February 2010 is not a general phenomenon, as one only observes this increase for those aged 20-24 (Panel C). Third, our results are not sensitive to excluding January and February 2010 (see column 2 in Table 4). Generally, this finding highlights that there is volatility in the data, particularly for young people, and that, hence, single 
coefficient estimates in Table 6 should not be given too much weight.

\section{Effects on the length of hospital stay}

So far, we have examined the ban's effect on alcohol-related hospitalizations at the extensive margin. This subsection takes into account the intensive margin by investigating the ban's effect on the length of stay. Due to higher health care costs associated with longer hospitalizations this is of direct policy relevance. The length of stay can be also interpreted as an indicator for the severity of hospitalization. The additional data set from one large hospital in the control group reveals a strong and positive correlation between the length of stay for alcohol-related hospitalizations and the number of additional diagnoses, the number of medical procedures, and whether artificial respiration was administered or an operation took place. ${ }^{45}$ In the hospital diagnosis statistics, length of stay is defined as the difference between the day of release and the day of admission. Correspondingly, individuals who enter and leave hospital on the same calendar day are counted as having spent zero days in the hospital.

A priori, it is not clear whether we should expect the ban to decrease or to increase the length of stay. Hospitalizations can be expected to be shorter if, for some individuals, the ban only limits the excessive consumption of alcohol without fully preventing the excess. However, it might also be that the ban prevents hospitalizations only in borderline cases and that the behavior of the more extreme cases is left unchanged by the ban. In this case, we would expect the average length of hospital stay to increase, as only the more severe cases are admitted. Furthermore, the length of stay might also increase because individuals buy the alcohol before 10pm, i.e., during legal hours of sale, and shift their excessive alcohol consumption to earlier in the day. In this case, it might be that more individuals enter the hospital before midnight and are counted in the hospital statistics as having spent one more day in the hospital than those who were admitted after midnight. Unfortunately, we do not observe the time of admission directly in our data. However, it is possible to investigate whether the ban decreases the probability of entering and leaving the hospital on the same day.

The first column of Table 7 presents the results of a specification similar to equation (2), which, however, deviates in the outcome (number of days in hospital) and the estimation method (negative binomial regression). Furthermore, the analysis is performed on the individual level to take into account the skewed distribution of the duration of stay. ${ }^{46}$

\footnotetext{
${ }^{45}$ The correlation coefficients between the length of stay in days and the number of medical procedures or number of additional diagnoses, respectively, are 0.79 and 0.71 . The correlation coefficients with the dummy variables operation and artificial respiration are 0.36 and 0.43 , respectively.

${ }^{46}$ For instance, while the mean hospitalization time for excessive alcohol consumption is 1.4 days for individuals aged 15-19, 90 percent of cases in this age group do not stay in the hospital longer than one
} 
Additionally, we include a full set of age dummies for both genders. ${ }^{47}$

While we find a small but significant increase in the length of hospitalization for adolescents, we obtain no significant effect on the length of stay for individuals aged 20-24. In contrast, for individuals aged 25-29 we find a reduction of the length of stay, being significant at the one percent level. These results do not change qualitatively when considering only cases with fewer than 30 days of hospitalization or when estimating an OLS-specification with the outcome in logs (results not shown).

Columns two and three of that table further investigate which margins contribute to the estimated effects on the length of stay. The second column presents the results of a linear probability model, where the outcome is a binary variable that indicates whether an ARH stay is longer than one day, i.e., two or more days. The variables on the right-hand side are the same as in the previous specification. For young adults (Panel C), the ban decreases the probability of staying in the hospital for more than one day. However, for adolescents (Panel B), the previously significantly positive effect becomes negative and insignificant.

The outcome in the third column indicates whether an individual stayed one or more days in the hospital (compared to individuals who entered and left on the same day). Hence, columns two and three differ only with respect to the classification of individuals with a length of stay of exactly one day. For individuals aged 15-19, the probability of staying at least one day increases by about two percentage points. In other words, for adolescents, the ban decreases the probability of leaving the hospital on the day of admission. This finding is in line with the idea that more adolescents are admitted to hospital before midnight as they shift their excessive consumption of alcohol to earlier hours. For young adults, we observe a similar pattern. Yet, the coefficient is not statistically significant.

\section{Effects on other diagnoses}

This subsection analyzes whether the late-night ban on the sale of alcoholic beverages also affects other hospitalizations, such as hospitalizations due to head and neck injuries, excessive consumption of illicit drugs, and, as a placebo outcome, lower respiratory diseases. All regressions in this subsection are based on equation (2). The only difference

day. This also includes individuals who enter and leave hospital on the same day. Mean ARH duration is 3.1 for individuals aged $20-24$, while 75 percent of these cases do not stay longer than one day. The respective numbers are 6.6 and 51 percent for individuals aged 25-29 and 10 and 25 percent for individuals aged 30 and above. The figures in this footnote relate to the situation in Baden-Württemberg in the pre-treatment period.

${ }^{47}$ Note that due to data confidentiality regulations, the length of stay variable is capped at 85 days in the hospital diagnosis data. However, the degree of censoring is very small (about 1 in 500 cases). Excluding these observations or estimating censored count data models (which due to the large sample size is only computationally possible for Panels B, C and D) produces very similar results. 
is that here, the outcome is defined as the monthly number of hospitalizations with the respective diagnoses per 100,000 inhabitants of the same age in that county.

First, we consider whether the ban also influences hospitalizations due to diseases of the lower respiratory system. ${ }^{48}$ We use this outcome for another placebo test. The fourth column of Table 7 demonstrates that the ban has no significant effects on hospitalizations due to diseases of the lower respiratory system.

Next, we investigate whether the ban has also consequences for drug-related hospitalizations. There is a discussion in the literature whether illicit drugs and alcohol are substitutes or complements (see e.g. Williams et al. 2004; Crost and Guerrero 2012; Conover and Scrimgeour 2013; Kelly and Rasul 2014). Our estimates might provide additional insights into this debate as the ban can be regarded as an exogenous reduction in excessive alcohol consumption for adolescents and young adults. If alcohol and drugs are substitutes, it might be that the ban on late-night alcohol sales has the unintended consequence of increasing drug-related hospitalizations. However, if alcohol and drugs are complements, we would expect fewer drug-related hospitalizations due to the ban. ${ }^{49}$ The fifth column of Table 7 does not provide evidence that the late-night ban on alcohol sales decreases drug-related hospitalizations in the general population. In fact, there is no empirical evidence in any age group that drug-related hospitalizations decrease after the ban. For adolescents and adults aged 25-29, we obtain a positive sign of the estimated effect. Note, however, that this effect is only significant for adolescents at the ten percent level and both effects disappear once we control for county-specific time-trends (not shown in the table). Therefore, we do not want to overinterpret this result.

The last column of Table 7 contributes to our understanding of whether the ban might also result in fewer head and neck injuries. ${ }^{50}$ These injuries are often related to violent assaults (Grundel and Blättner 2010), and the relationship between alcohol and the propensity to being involved in violent assaults (both as offender and as victim) is uncontested. As other age groups might be victims of violent assaults under the influence of alcohol as well, we might also expect reductions in hospitalizations due to head and neck injuries for age groups in which we do not find significant reductions in ARH rates. However, we do not know the exact reason for the head or neck injury. Some cases might be unrelated to

\footnotetext{
${ }^{48}$ This relates to the ICD-10 codes J09-J22 and J40-J47 and includes influenza, pneumonia, and bronchitis, among others.

${ }^{49}$ In order to code drug-related hospitalizations, we follow Kelly and Rasul (2014) in relying on the codes for mental and behavioral disorders due to using opioids (F11), cannabinoids (F12), cocaine (F14), and hallucinogens (F16), as well as on the code for poisoning by narcotics and psychodysleptics (T40). The codes X42, X62 and Y12 do not appear in our data set.

${ }^{50}$ We rely on the ICD-10 codes S00-S19 since Grundel and Blättner (2010: 17) report that these codes (injuries of head and neck) are the most common physical consequences of violent assaults. Head injuries are by far more common than neck injuries in our hospitalization data and the results are robust to only considering head injuries.
} 
violent assaults but related to alcohol, e.g., head injuries after bicycle accidents under the influence of alcohol. Nevertheless, this category might include numerous cases that have nothing to do with violent assaults or alcohol, thereby increasing the measurement error in the outcome variable. When considering all age groups together (Panel A) or looking at the age groups 20-24 or 30 and older, we obtain a statistically significant reduction of head and neck injuries following the ban. ${ }^{51}$ We interpret this as an indication that the ban might have other beneficial effects on top of reducing alcohol-related hospitalizations. However, this preliminary conclusion requires further investigation as our hospital data do not include detailed information about the reason for the injury.

\section{Conclusion}

The question of how to effectively reduce binge drinking among young people is of perennial importance given the increasing numbers of alcohol-related hospitalizations among adolescents and young adults in many industrialized countries. This study exploits the introduction of a ban on late-night off-premise alcohol sales and estimates its impact on alcohol-related hospitalizations.

We find that the policy change in the German state of Baden-Württemberg reduces alcohol-related hospitalizations among adolescents and young adults in the short term by about seven percent. This corresponds to a reduction of 3.35 hospital admissions in adolescents (ages 15-19) and 1.98 in young adults (ages 20-24) per month and 100,000 same-aged individuals. Regardless of whether we compare alcohol-related hospital admissions in Baden-Württemberg to admissions in all other states, in the western German states, in the southern states of Bavaria or Hesse, or in a synthetic control group, we find that the implementation of the late-night off-premise alcohol ban significantly reduces alcohol-related hospital admissions among young people. Moreover, we present estimates for several alternative specifications to probe the robustness of our findings. All of these robustness exercises confirm a significant decline in alcohol-related hospitalizations among adolescents and young adults. Furthermore, we provide evidence that the estimated effects are not driven by single events or single months. There is no evidence, however, that the ban reduces alcohol-related hospitalization rates among individuals in older age groups. We show that the ban impacts both male and female adolescents and young adults, though the effect on males is stronger. There is also evidence of a decrease in the number of hospitalizations due to violent assault as a result of the ban. However, we do not find evidence that the ban reduces drug-related hospitalizations.

\footnotetext{
${ }^{51}$ These results are robust to various changes in the model specification, e.g. a shorter analysis period, the inclusion of county-specific time trends, and the exclusion of the time-varying control variables.
} 
According to our estimates, the ban prevented alcohol-related hospitalizations for about 444 adolescents and 288 young adults in the 22 months after its enactment in March 2010. The Techniker Krankenkasse, a large German health insurer, estimates that on average each alcohol-related hospitalization of an adolescent costs about 540 euros. ${ }^{52}$ Taking the 540 euros at face value, our estimates indicate that the German statutory health insurance system saved about 396,000 euros as a result of the ban. This represents a lower bound of the total health costs for various reasons. First, the amount of 540 euros per hospital stay includes only the direct short-run costs incurred by the health insurer. It does not include the cost of any subsequent treatments. Second, we only observe the main diagnosis in our hospitalization data. However, the ban might also reduce hospitalizations where alcohol is only a secondary diagnosis and hospitalizations that are more indirectly related to alcohol (e.g., hospitalization due to head and neck injuries). Third, the calculated amount does not include any short-run and long-run costs borne by the individuals themselves. Fourth, we are only looking at an extreme form of binge drinking, namely the kind that ends up at hospitals. It might be that health costs are being reduced further if the ban reduces other forms of binge drinking as well. Additionally, the amount of 396,000 euros does not include any non-health costs (e.g., potential reductions in alcohol-related crime, sick leave, and traffic accidents).

The main finding of this paper is that the late-night off-premise alcohol sales ban is effective at reducing alcohol-related hospitalizations among adolescents and young adults in the short term. This finding is important since there is a large literature documenting adverse health effects of excessive alcohol consumption. Furthermore, adolescence and young adulthood are often seen as key ages for the prevention of alcoholism (Enoch 2006). The findings are likely to be informative for policy debates in a number of jurisdictions in Germany and in other countries that are thinking about implementing late-night alcohol sales bans. ${ }^{53}$ This study provides evidence of the benefits of such a ban. However, these benefits have to be weighed against the potential losses to owners of off-premise outlets and especially against the encroachment upon individual liberties. Although the ban is a rather "light touch" regulation (as it is easy to avoid legally by buying the alcohol before $10 \mathrm{pm}$ or by going to bars), it is still an incursion into the private sphere. This tradeoff cannot be resolved by researchers: policy-makers and, hence, voters are ultimately responsible for this decision.

\footnotetext{
${ }^{52}$ See http://www.welt.de/2108614, accessed July 22, 2014. The health insurer bases its calculations on an average hospital stay of about 1.2 days, which fits the average length of hospital stays among the adolescents and young adults in our data.

${ }^{53}$ Indeed, several other German states are considering the implementation of similar policies (see http: //www.faz.net/-gpg-15w1k, accessed July 23, 2014).
} 


\section{Acknowledgement}

We would like to thank Silke Anger, Michael Bahrs, Deborah Anne Bowen, Jörg Breitung, Mirko Draca, Jan Göbel, Maia Güell, Dan Hamermesh, Timo Hener, Adam Lederer, Sandra McNally, Johannes Möller, Petra Persson, Frauke Peter, Erik Plug, Max Podstawski, Imran Rasul, Claudia Schaefer, Tobias Schmidt, and Conny Wunsch for helpful comments and suggestions. Further thanks go to participants in various conferences and seminars. The hospital diagnosis statistics were provided by the statistical offices of the 16 Länder and the Federal Statistical Office of Germany. We thank the team of the Research Data Center of the Statistical Office of Berlin and Brandenburg for helpful comments regarding these data. Thomas Apolke, Andreas Deneke and Jakob Simonsen contributed valuable research assistance. 
Figure 1: Trends in alcohol-related hospitalizations

(a)

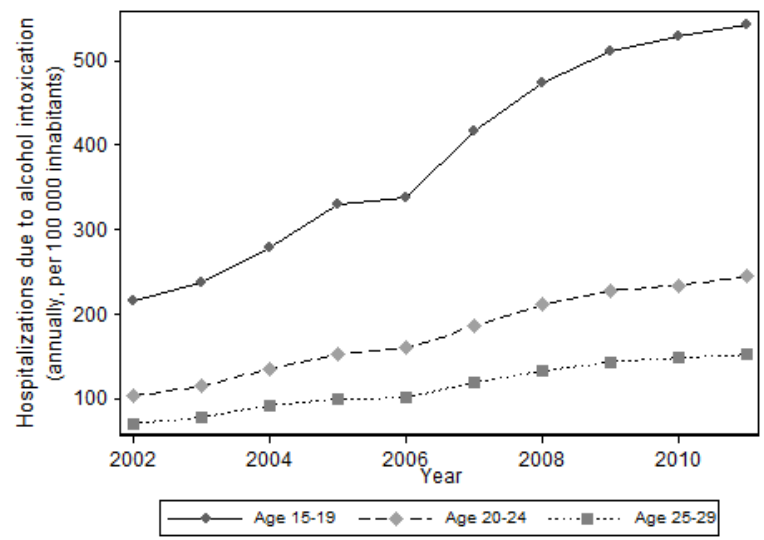

(b)

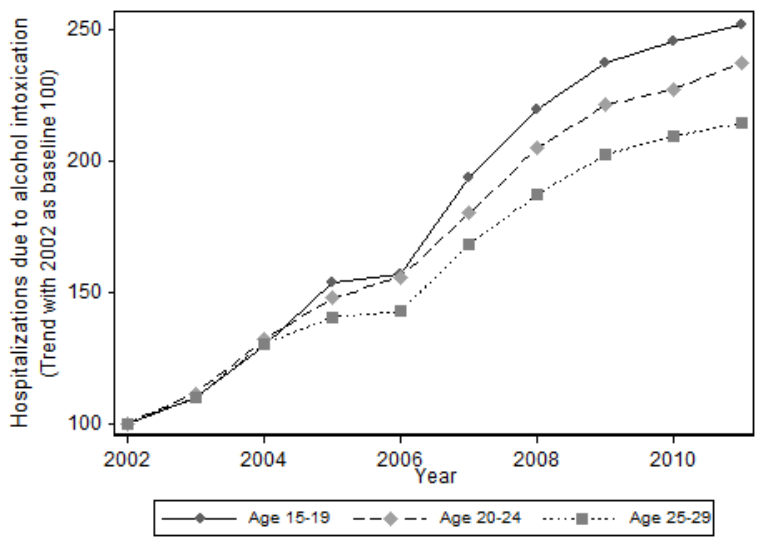

Note: The figure displays trends in alcohol-related hospitalization rates in various age groups of young people (15-19, 20-24, 25-29) between 2002 and 2011. Panel (a) provides the annual number of alcoholrelated hospitalizations per 100,000 inhabitants of the same age. Panel (b) shows growth rates of these alcohol-related hospitalizations compared to the base year 2002. Source: German Federal Statistical Office 2014. 
Figure 2: Hours of admission of alcohol-related hospitalizations

(a) Overall

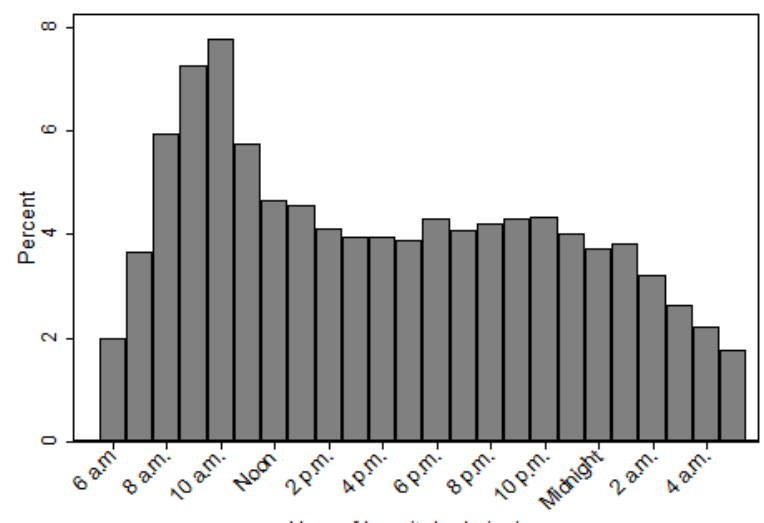

Hour of hospital admission

(c) Age 20-24

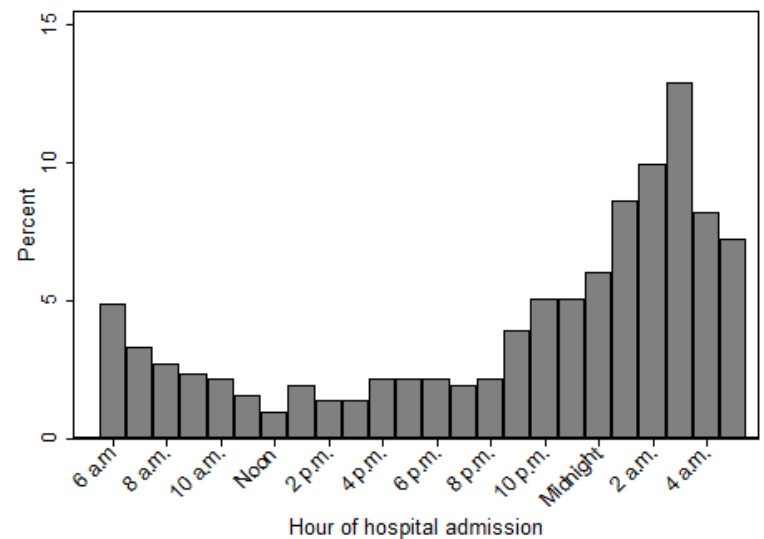

(e) Age 30+

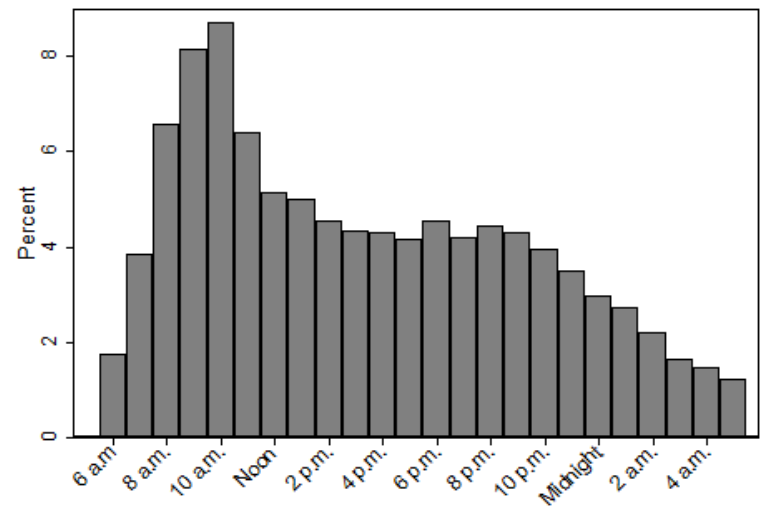

Hour of hospital admission (b) Age 15-19

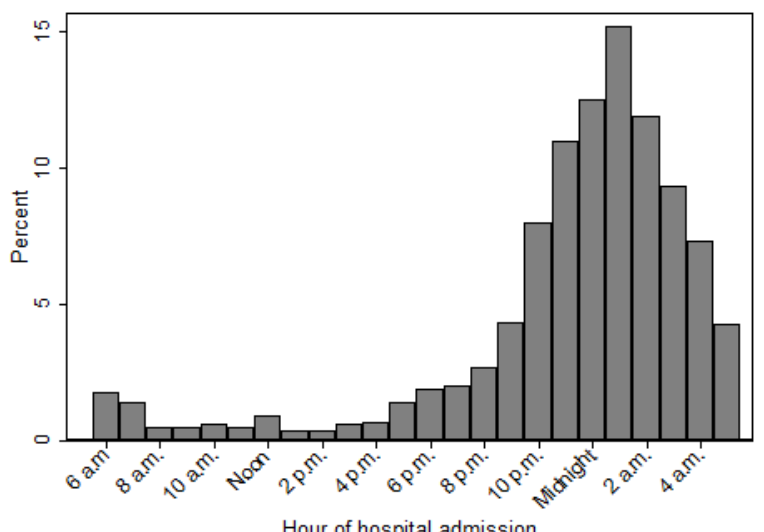

(d) Age 25-29

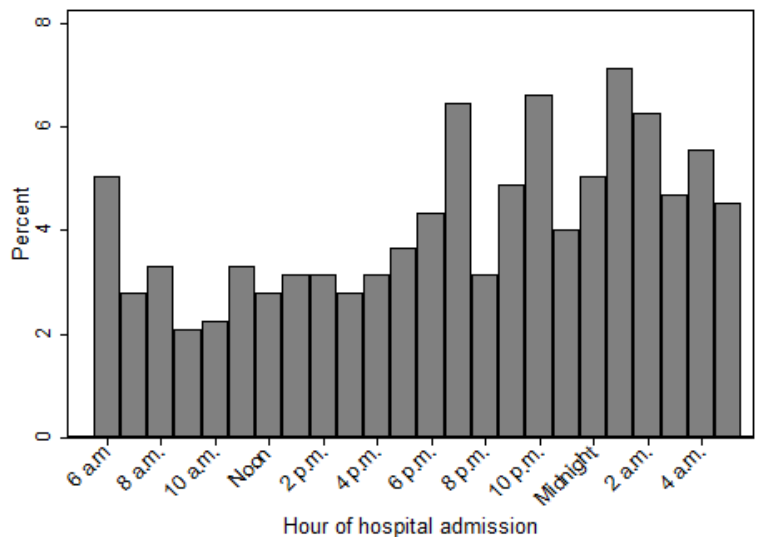

Note: The figure shows the distribution of admission times of alcohol-related hospitalizations. Source: Data are from one large hospital in the control group, pooled over the years 2007-2013. 
Figure 3: Alcohol-related youth hospitalizations in 2009 by age and gender

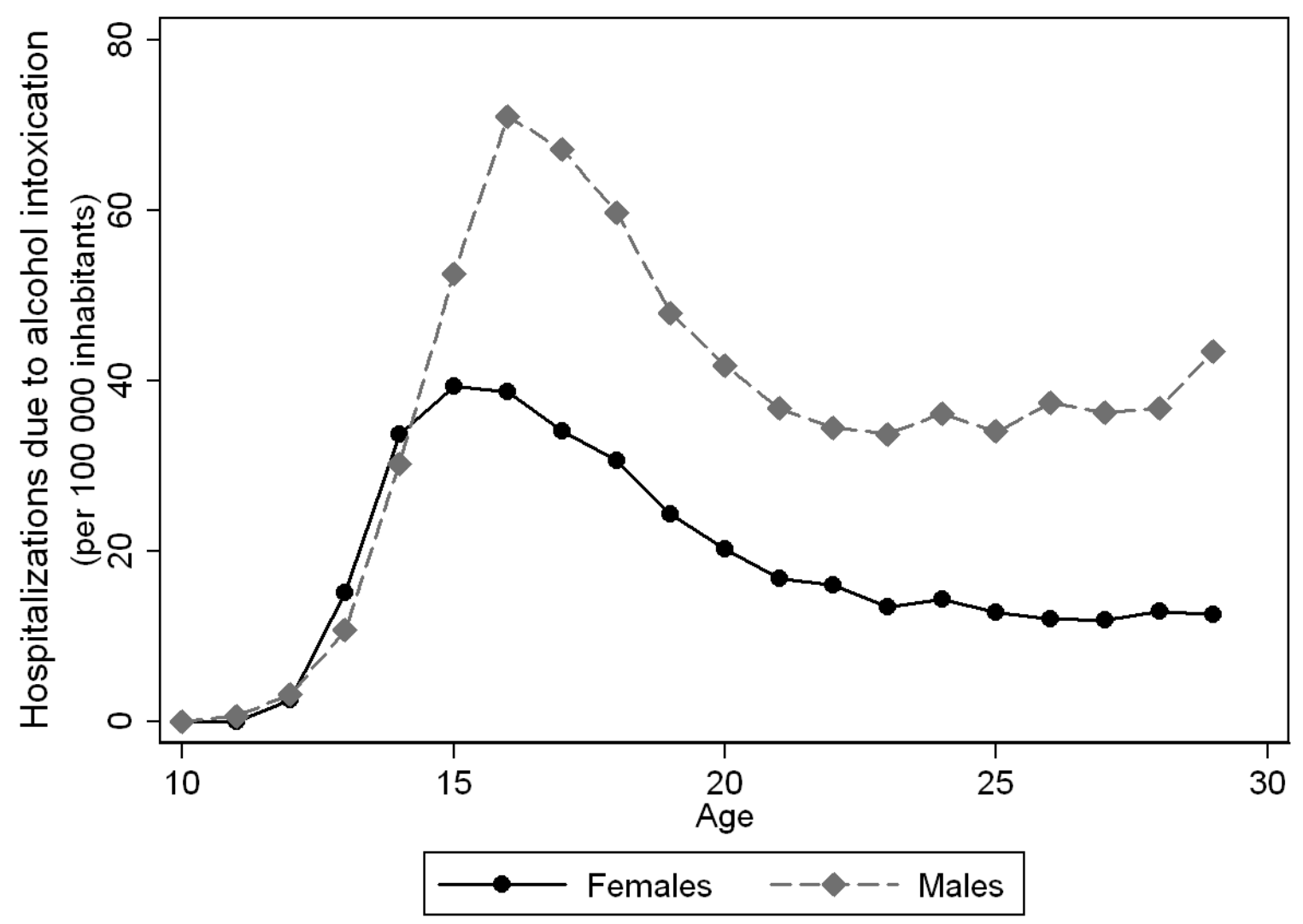

Note: The figure displays gender-specific alcohol-related hospitalization rates for various ages in Germany, i.e., the average monthly number of alcohol-related hospitalizations in 2009 per 100,000 inhabitants of the same age and gender. 
Figure 4: Trends in alcohol-related hospitalizations - treatment and control group

(a) Overall

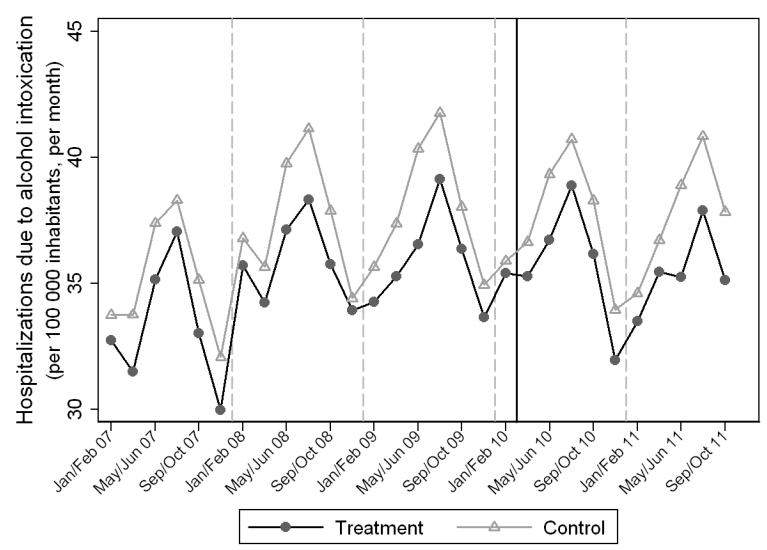

(c) Age 20-24

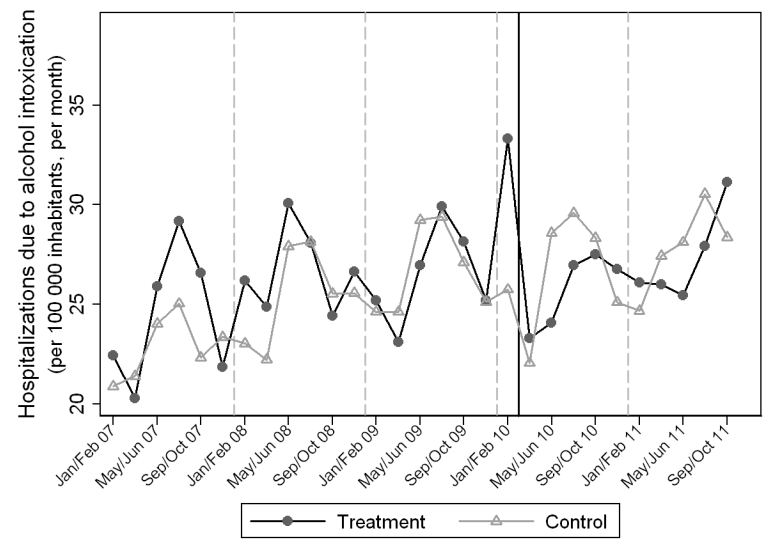

(e) Age 30+

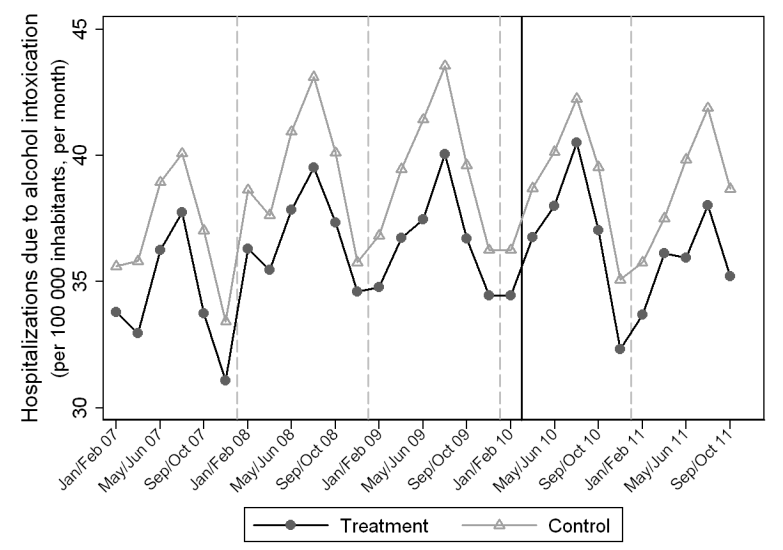

(b) Age 15-19

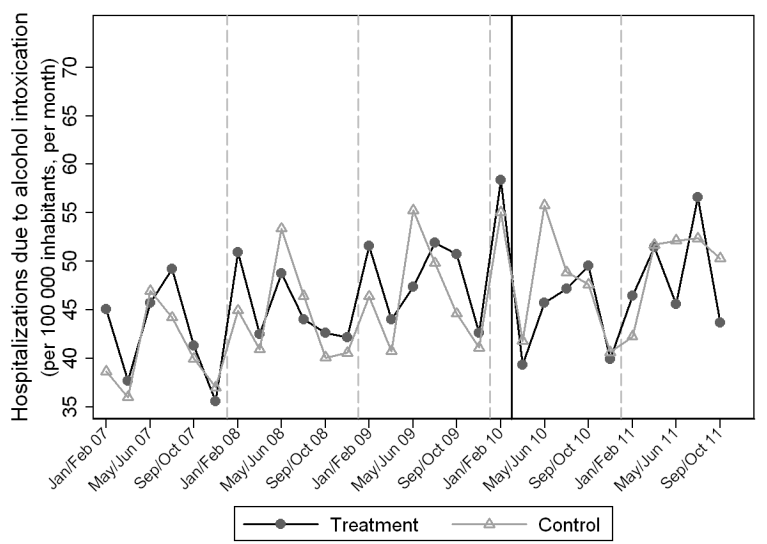

(d) Age 25-29

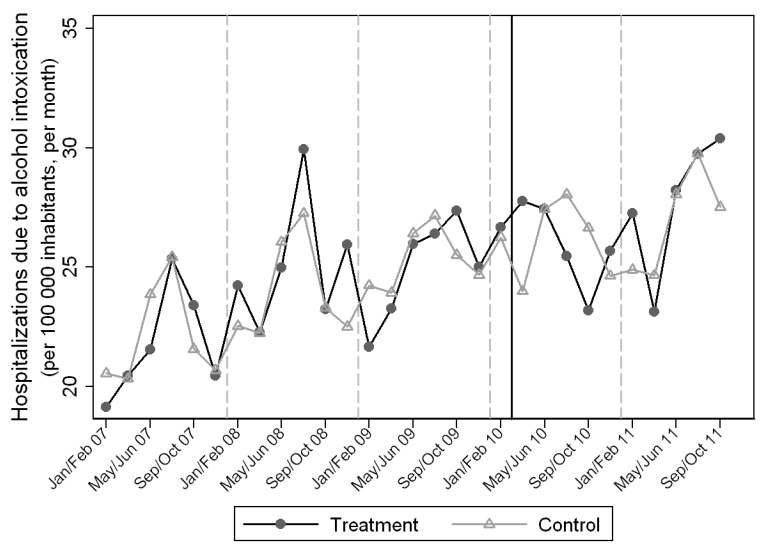

Note: The figure presents trends in the number of monthly alcohol-related hospitalizations per 100,000 same-aged inhabitants for treatment and control group, averaged over two months. The continuous vertical line indicates the introduction of the late-night ban on alcohol sales in the treatment state on March 1, 2010. 
Figure 5: Treatment effect by ages

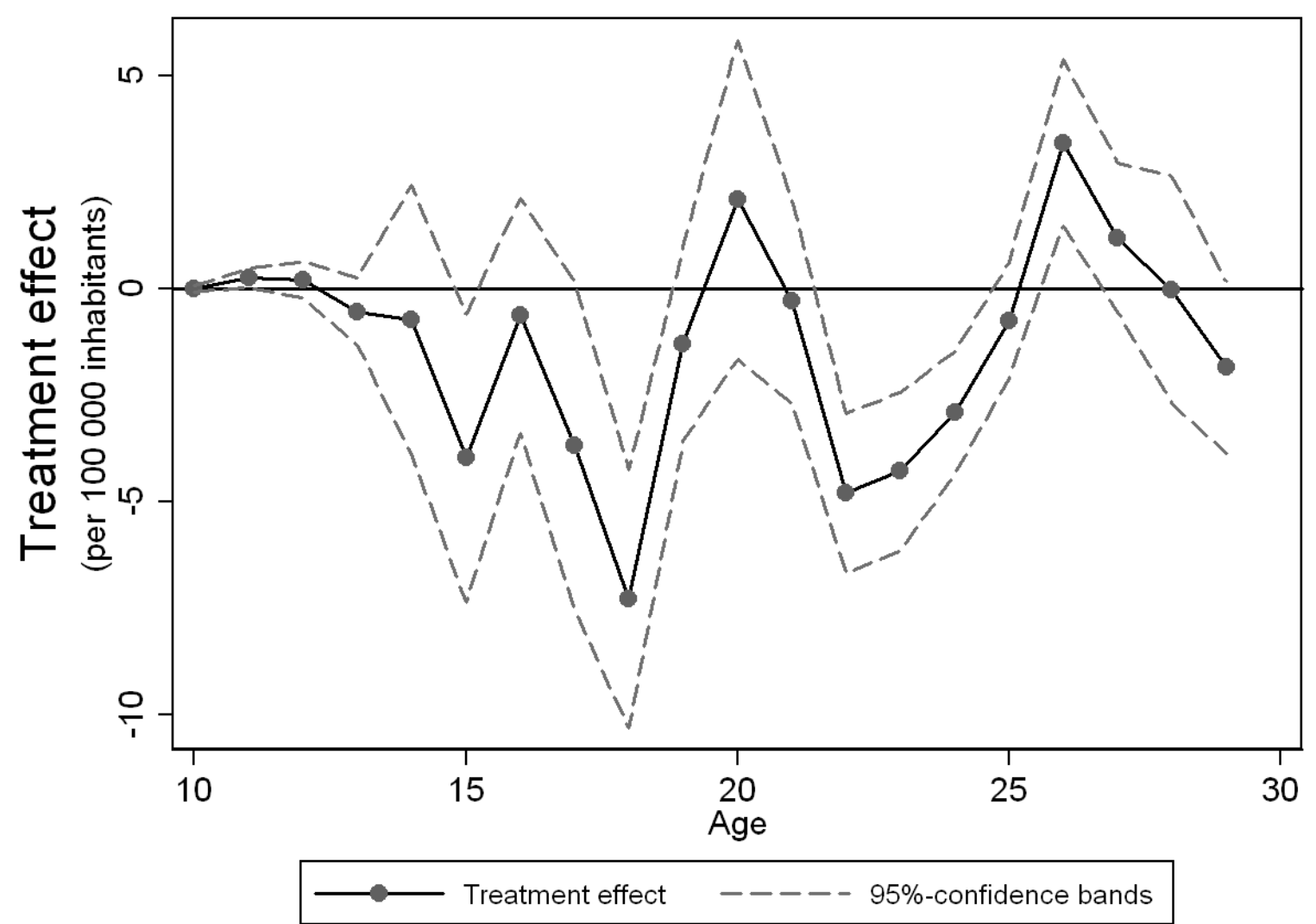

Note: The figure displays the estimated impact of the ban for single age years and the corresponding confidence bands. The vertical axis displays the effect of the ban in terms of monthly alcohol-related hospitalization rates per 100,000 inhabitants of the same age. 
Table 1: Basic difference-in-differences results

\begin{tabular}{|c|c|c|c|c|}
\hline & Before & After & Difference & \%-change \\
\hline \multicolumn{5}{|c|}{ Panel A: Overall } \\
\hline Treatment & 35.00 & 35.14 & 0.14 & \\
\hline Control & 36.84 & 37.22 & 0.39 & \\
\hline Difference & -1.84 & -2.08 & -0.25 & -0.70 \\
\hline \multicolumn{5}{|c|}{ Panel B: Age 15-19 } \\
\hline Treatment & 45.87 & 46.09 & 0.22 & \\
\hline Control & 44.20 & 48.05 & 3.84 & \\
\hline Difference & 1.66 & -1.96 & -3.62 & -7.29 \\
\hline \multicolumn{5}{|c|}{ Panel C: Age 20-24 } \\
\hline Treatment & 26.25 & 26.67 & 0.43 & \\
\hline Control & 25.03 & 27.13 & 2.11 & \\
\hline Difference & 1.22 & -0.46 & -1.68 & -5.92 \\
\hline \multicolumn{5}{|c|}{ Panel D: Age 25-29 } \\
\hline Treatment & 24.06 & 26.73 & 2.67 & \\
\hline Control & 23.92 & 26.35 & 2.44 & \\
\hline Difference & 0.15 & 0.38 & 0.23 & 0.87 \\
\hline \multicolumn{5}{|c|}{ Panel E: Age 30+ } \\
\hline Treatment & 35.85 & 35.77 & -0.08 & \\
\hline Control & 38.44 & 38.29 & -0.15 & \\
\hline Difference & -2.59 & -2.52 & 0.07 & 0.19 \\
\hline
\end{tabular}

Note: Average monthly alcohol-related hospitalizations per 100,000 inhabitants in the respective age group before and after the policy change for treatment (Baden-Württemberg) and control group (all other states). The last column indicates percentage changes in alcohol-related hospitalizations due to the reform. 
Table 2: The ban's effect on alcohol-related hospitalizations - main results

\begin{tabular}{|c|c|c|c|c|}
\hline & \multicolumn{3}{|c|}{+ time/county } & $\begin{array}{l}\text { + state-spec. } \\
\text { seasonal eff. }\end{array}$ \\
\hline \multicolumn{5}{|c|}{ Panel A: Overall } \\
\hline Effect & $\begin{array}{c}-0.25 \\
(0.21)\end{array}$ & $\begin{array}{c}-0.31 \\
(0.20)\end{array}$ & $\begin{array}{c}-0.69 * * * \\
(0.10)\end{array}$ & $\begin{array}{c}-0.56 * * * \\
(0.11)\end{array}$ \\
\hline$\%$-change & -0.70 & -0.86 & -1.92 & -1.57 \\
\hline \multicolumn{5}{|c|}{ Panel B: Age 15-19 } \\
\hline Effect & $\begin{array}{c}-3.62 * * * \\
(1.01)\end{array}$ & $\begin{array}{c}-3.44 * * * \\
(0.98)\end{array}$ & $\begin{array}{c}-3.79 * * * \\
(1.09)\end{array}$ & $\begin{array}{c}-3.35 * * \\
(1.15)\end{array}$ \\
\hline$\%$-change & -7.29 & -6.94 & -7.61 & -6.77 \\
\hline \multicolumn{5}{|c|}{ Panel C: Age 20-24 } \\
\hline Effect & $\begin{array}{c}-1.68 * * \\
(0.65)\end{array}$ & $\begin{array}{c}-1.76 * * \\
(0.61)\end{array}$ & $\begin{array}{l}-2.16 * * * \\
(0.60)\end{array}$ & $\begin{array}{c}-1.98 * * * \\
(0.60)\end{array}$ \\
\hline \%-change & -5.92 & -6.19 & -7.49 & -6.89 \\
\hline \multicolumn{5}{|c|}{ Panel D: Age 25-29 } \\
\hline Effect & $\begin{array}{c}0.23 \\
(0.54)\end{array}$ & $\begin{array}{c}0.13 \\
(0.55)\end{array}$ & $\begin{array}{c}0.18 \\
(0.60)\end{array}$ & $\begin{array}{c}0.20 \\
(0.61)\end{array}$ \\
\hline$\%$-change & 0.88 & 0.48 & 0.68 & 0.75 \\
\hline \multicolumn{5}{|c|}{ Panel E: Age 30+ } \\
\hline Effect & $\begin{array}{c}0.07 \\
(0.25)\end{array}$ & $\begin{array}{c}0.03 \\
(0.25)\end{array}$ & $\begin{array}{r}-0.25 \\
(0.15)\end{array}$ & $\begin{array}{r}-0.14 \\
(0.16)\end{array}$ \\
\hline \%-change & 0.19 & 0.07 & -0.69 & -0.39 \\
\hline
\end{tabular}

Note: The table displays the reform's effect on the monthly number of alcohol-related hospitalizations per 100,000 inhabitants for various age groups, together with its standard error clustered on the state level (in parentheses). The last line in each panel indicates the percentage change in alcohol-related hospitalizations due to the reform. All regressions are weighted by the population of the respective age group in the county, and based on 24,120 county-month observations. The first column repeats the results of the basic difference-in-differences results from Table 1, the second column includes fixed effects for the 402 counties as well as for the 60 months. Additionally, the third column includes time-varying control variables on the county and state level. The last column adds state-specific seasonal dummies. ${ }^{*} p<0.1$; ** $p<0.05$;** $p<0.01$. 
Table 3: The ban's effect on alcohol-related hospitalizations - different control groups

\begin{tabular}{|c|c|c|c|c|}
\hline & $\begin{array}{c}\text { All } \\
\text { states }\end{array}$ & $\begin{array}{l}\text { Western } \\
\text { states }\end{array}$ & $\begin{array}{l}\text { Southern } \\
\text { states }\end{array}$ & $\begin{array}{c}\text { Synthetic } \\
\text { control group }\end{array}$ \\
\hline \multicolumn{5}{|c|}{ Panel A: Overall } \\
\hline Effect & $\begin{array}{c}-0.56 * * * \\
(0.11)\end{array}$ & $\begin{array}{c}-0.48 * * \\
(0.15)\end{array}$ & $\begin{array}{r}-0.69 \\
(0.40)\end{array}$ & $\begin{array}{c}-0.64 * * \\
(0.30)\end{array}$ \\
\hline \%-change & -1.57 & -1.36 & -1.92 & -1.80 \\
\hline \multicolumn{5}{|c|}{ Panel B: Age 15-19 } \\
\hline Effect & $\begin{array}{c}-3.35 * * \\
(1.15)\end{array}$ & $\begin{array}{c}-3.62 * * * \\
(1.09)\end{array}$ & $\begin{array}{c}-5.75 \\
(2.17)\end{array}$ & $\begin{array}{c}-4.23 * * * \\
(0.98)\end{array}$ \\
\hline \%-change & -6.77 & -7.28 & -11.09 & -8.40 \\
\hline \multicolumn{5}{|c|}{ Panel C: Age 20-24 } \\
\hline Effect & $\begin{array}{c}-1.98 * * * \\
(0.60)\end{array}$ & $\begin{array}{l}-2.00 * * * \\
(0.57)\end{array}$ & $\begin{array}{c}-2.98 * \\
(0.80)\end{array}$ & $\begin{array}{l}-2.44 * * \\
(0.94)\end{array}$ \\
\hline \%-change & -6.89 & -6.98 & -10.04 & -8.39 \\
\hline \multicolumn{5}{|c|}{ Panel D: Age 25-29 } \\
\hline Effect & $\begin{array}{c}0.20 \\
(0.61)\end{array}$ & $\begin{array}{c}0.06 \\
(0.59)\end{array}$ & $\begin{array}{c}0.24 \\
(1.36)\end{array}$ & $\begin{array}{c}0.32 \\
(0.73)\end{array}$ \\
\hline$\%$-change & 0.75 & 0.21 & 0.91 & 1.22 \\
\hline \multicolumn{5}{|c|}{ Panel E: Age 30+ } \\
\hline Effect & $\begin{array}{c}-0.14 \\
(0.16)\end{array}$ & $\begin{array}{c}-0.17 \\
(0.23)\end{array}$ & $\begin{array}{r}-0.17 \\
(0.13)\end{array}$ & $\begin{array}{c}0.10 \\
(0.27)\end{array}$ \\
\hline \%-change & -0.39 & -0.48 & -0.47 & 0.28 \\
\hline $\mathrm{N}$ & 24,120 & 19,500 & 10,560 & 24,120 \\
\hline
\end{tabular}

Note: All specifications are based on the specification in the last column of Table 2. See also the note below that table. The synthetic control group in the last column is built on a reweighted control group that follows exactly the same trend as the treatment group prior to the introduction of the ban. ${ }^{*} p<0.1$; ** $p<0.05$;*** $p<0.01$. 


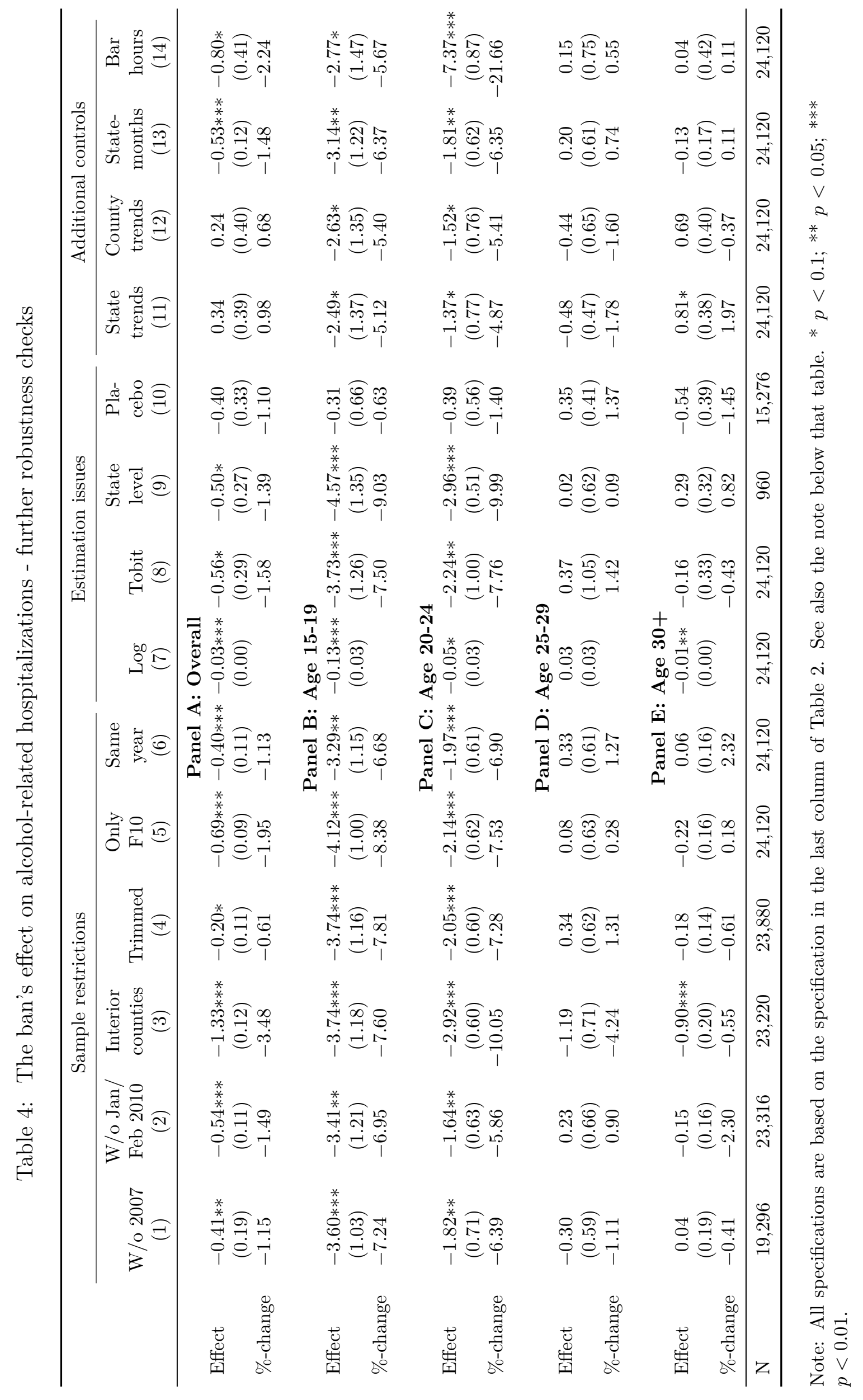


Table 5: Differential effects of the ban for men and women

\begin{tabular}{|c|c|c|}
\hline & Females & Males \\
\hline \multicolumn{3}{|c|}{ Panel A: Overall } \\
\hline Effect & $\begin{array}{c}-0.35 * * * \\
(0.12)\end{array}$ & $\begin{array}{c}-0.83 * * * \\
(0.23)\end{array}$ \\
\hline$\%$-change & -1.79 & -1.58 \\
\hline \multicolumn{3}{|c|}{ Panel B: Age 15-19 } \\
\hline Effect & $\begin{array}{c}-1.97 * \\
(1.03)\end{array}$ & $\begin{array}{c}-4.74 * * * \\
(1.44)\end{array}$ \\
\hline$\%$-change & -5.62 & -7.50 \\
\hline \multicolumn{3}{|c|}{ Panel C: Age 20-24 } \\
\hline Effect & $\begin{array}{c}-1.76 * * * \\
(0.45)\end{array}$ & $\begin{array}{c}-2.18 * \\
(1.05)\end{array}$ \\
\hline \%-change & -9.74 & -5.62 \\
\hline \multicolumn{3}{|c|}{ Panel D: Age 25-29 } \\
\hline Effect & $\begin{array}{l}1.35 * * \\
(0.51)\end{array}$ & $\begin{array}{r}-0.79 \\
(0.83)\end{array}$ \\
\hline \%-change & 11.23 & -1.94 \\
\hline \multicolumn{3}{|c|}{ Panel E: Age 30+ } \\
\hline Effect & $\begin{array}{c}-0.23 \\
(0.19)\end{array}$ & $\begin{array}{r}-0.08 \\
(0.23)\end{array}$ \\
\hline$\%$-change & -1.20 & -0.16 \\
\hline
\end{tabular}

Note: All specifications are based on the specification in the last column of Table 2. See also the note below that table. ${ }^{*} p<0.1 ;{ }^{* *} p<0.05$; ${ }^{* * *} p<0.01$. 


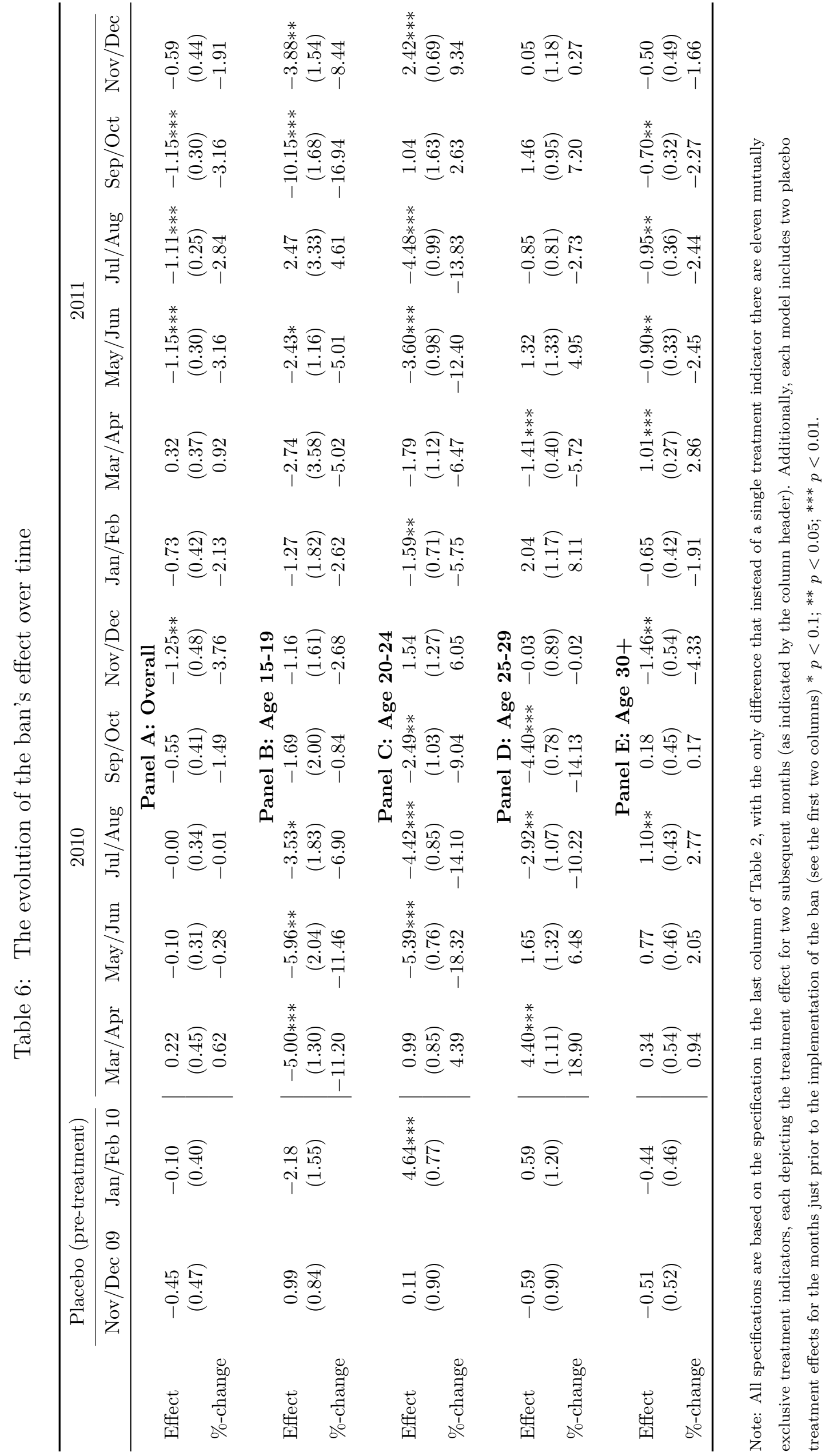


Table 7: Other outcomes

\begin{tabular}{|c|c|c|c|c|c|c|}
\hline & $\begin{array}{l}\text { Length } \\
\text { of stay } \\
\text { (1) }\end{array}$ & $\begin{array}{c}\text { Prob. } \\
\text { stay }>1 \text { day } \\
(2)\end{array}$ & $\begin{array}{c}\text { Prob. } \\
\text { stay } \geq 1 \text { day } \\
(3)\end{array}$ & $\begin{array}{l}\text { Respiratory } \\
\text { system } \\
(4)\end{array}$ & $\begin{array}{l}\text { Drugs } \\
(5)\end{array}$ & $\begin{array}{c}\text { Head } \\
\text { injuries } \\
(6)\end{array}$ \\
\hline \multicolumn{7}{|c|}{ Panel A: Overall } \\
\hline Effect & $\begin{array}{c}-0.008 \\
(0.041)\end{array}$ & $\begin{array}{l}0.012 * * * \\
(0.002)\end{array}$ & $\begin{array}{l}0.008 * * * \\
(0.001)\end{array}$ & $\begin{array}{c}-0.40 \\
(0.79)\end{array}$ & $\begin{array}{c}0.25 \\
(0.19)\end{array}$ & $\begin{array}{c}-0.92 * * \\
(0.35)\end{array}$ \\
\hline$\%$-change & -0.10 & 1.83 & 0.94 & -0.88 & 6.17 & -2.96 \\
\hline $\mathrm{N}$ & $1,080,954$ & $1,080,954$ & $1,080,954$ & 24,120 & 24,120 & 24,120 \\
\hline \multicolumn{7}{|c|}{ Panel B: Age 15-19 } \\
\hline Effect & $\begin{array}{l}0.072 * * * \\
(0.012)\end{array}$ & $\begin{array}{c}-0.005 \\
(0.004)\end{array}$ & $\begin{array}{l}0.019 * * * \\
(0.005)\end{array}$ & $\begin{array}{c}0.38 \\
(0.43)\end{array}$ & $\begin{array}{c}0.55 * \\
(0.26)\end{array}$ & $\begin{array}{c}-0.72 \\
(1.13)\end{array}$ \\
\hline$\%$-change & 4.32 & -4.80 & 4.31 & 3.94 & 10.20 & -1.26 \\
\hline $\mathrm{N}$ & 82,954 & 82,954 & 82,954 & 24,120 & 24,120 & 24,120 \\
\hline \multicolumn{7}{|c|}{ Panel C: Age 20-24 } \\
\hline Effect & $\begin{array}{c}-0.005 \\
(0.064)\end{array}$ & $\begin{array}{c}-0.014 * \\
(0.007)\end{array}$ & $\begin{array}{c}0.010 \\
(0.005)\end{array}$ & $\begin{array}{c}-0.18 \\
(0.23)\end{array}$ & $\begin{array}{c}0.04 \\
(0.50)\end{array}$ & $\begin{array}{c}-1.64 * * \\
(0.57)\end{array}$ \\
\hline$\%$-change & -0.18 & -6.56 & 2.42 & -2.42 & 0.37 & -3.70 \\
\hline $\mathrm{N}$ & 53,585 & 53,585 & 53,585 & 24,120 & 24,120 & 24,120 \\
\hline \multicolumn{7}{|c|}{ Panel D: Age 25-29 } \\
\hline Effect & $\begin{array}{c}-0.219 * * * \\
(0.082)\end{array}$ & $\begin{array}{c}-0.000 \\
(0.006)\end{array}$ & $\begin{array}{c}-0.005 \\
(0.007)\end{array}$ & $\begin{array}{c}0.15 \\
(0.24)\end{array}$ & $\begin{array}{l}2.02 * * \\
(0.92)\end{array}$ & $\begin{array}{c}0.33 \\
(0.42)\end{array}$ \\
\hline \%-change & -3.44 & -0.10 & -0.71 & 1.93 & 18.01 & 1.26 \\
\hline $\mathrm{N}$ & 51,917 & 51,917 & 51,917 & 24,120 & 24,120 & 24,120 \\
\hline \multicolumn{7}{|c|}{ Panel E: Age 30+ } \\
\hline Effect & $\begin{array}{c}-0.042 \\
(0.050)\end{array}$ & $\begin{array}{l}0.015 * * * \\
(0.002)\end{array}$ & $\begin{array}{l}0.006 * * * \\
(0.001)\end{array}$ & $\begin{array}{c}-0.54 \\
(0.99)\end{array}$ & $\begin{array}{c}0.09 \\
(0.12)\end{array}$ & $\begin{array}{c}-0.74 * * \\
(0.32)\end{array}$ \\
\hline$\%$-change & -0.44 & 2.04 & 0.67 & -0.98 & 3.37 & -2.66 \\
\hline $\mathrm{N}$ & 892,498 & 892,498 & 892,498 & 24,120 & 24,120 & 24,120 \\
\hline
\end{tabular}

Note: The first three columns show marginal effects of the ban on different measures of length of stay for alcohol-related hospitalizations. Unit of analysis is the individual hospitalization. The first column displays marginal effects from negative binomial regressions for the ban's effect on the number of days in hospital. The outcomes in the second and third column are binary variables indicating whether an individual stayed more than one day in hospital (column 2) or at least one day (column 3). The next three columns refer to the ban's effect on various other outcomes. Each outcome is defined as the monthly number of hospitalizations with the respective diagnoses per 100,000 inhabitants of the same age: hospitalizations due to diseases of the lower respiratory system (column 4), drug-related hospitalizations (column 5), and hospital stays due to head and neck injuries (column 6 ). ${ }^{*} p<0.1$; ${ }^{* *} p<0.05$; *** $p<0.01$. 
A. Appendix 
Figure A.1: Day of alcohol-related admission to hospital

(a) Overall

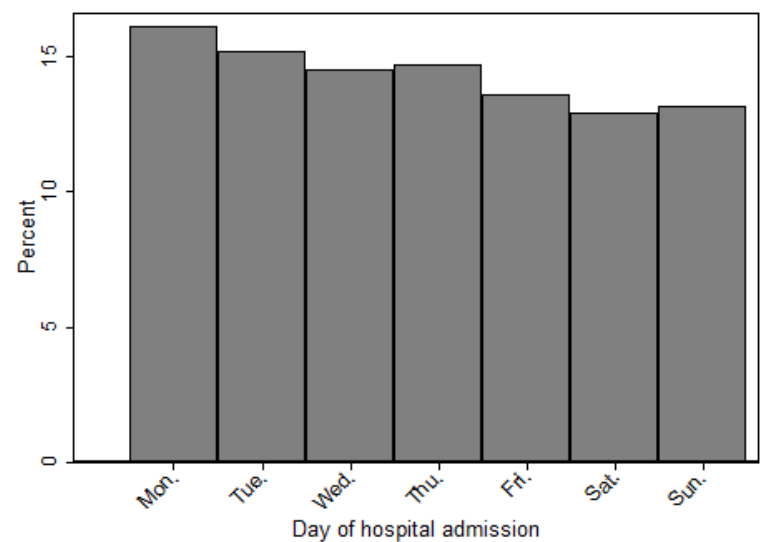

(c) Age 20-24

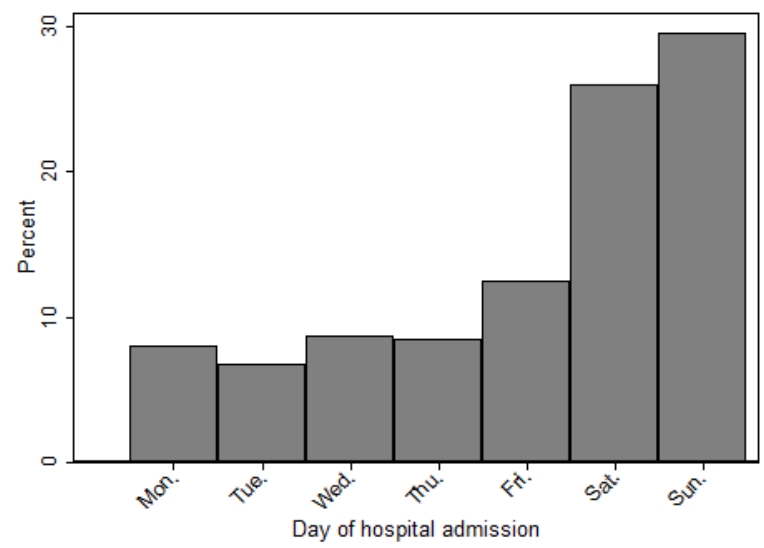

(e) Age 30+

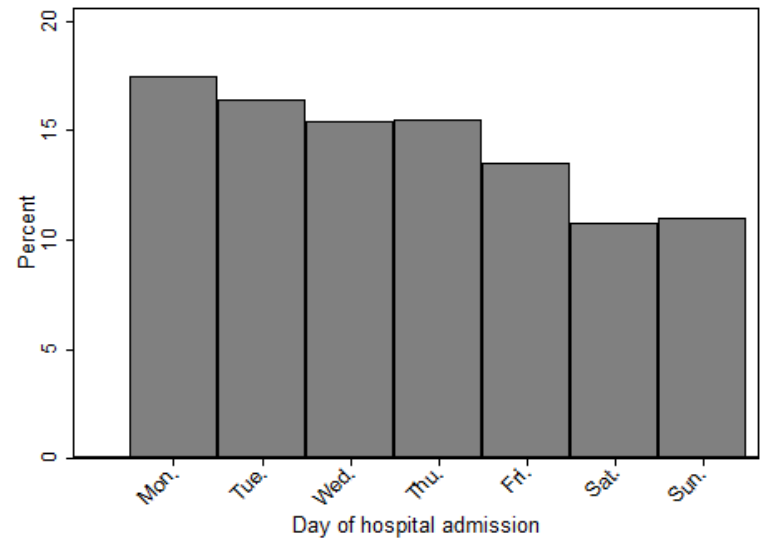

(b) Age 15-19

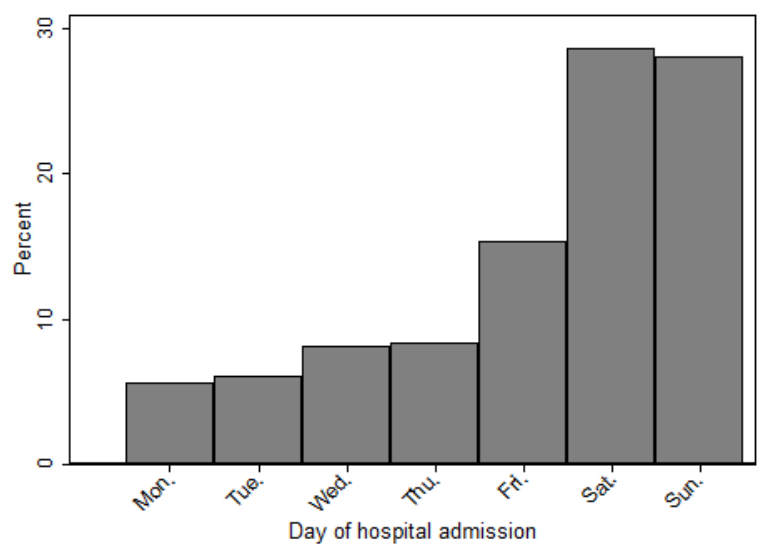

(d) Age 25-29

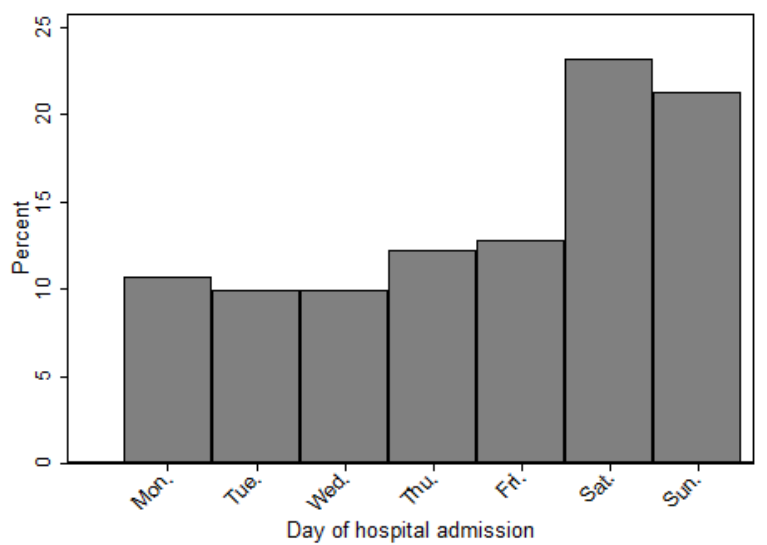

Note: The figure shows the distribution of days of admission of alcohol-related hospitalizations. Source: Data are from one large hospital in the control group, pooled over the years 2007-2013. 
Table A.1: The effect of the Bavarian bar hour extension

\begin{tabular}{|c|c|c|c|c|c|}
\hline & Basic DiD & $\begin{array}{c}+ \text { time/county } \\
\text { dummies }\end{array}$ & + controls & $\begin{array}{l}\text { + state-spec. } \\
\text { seasonal eff. }\end{array}$ & $\begin{array}{l}+ \text { state } \\
\text { trends }\end{array}$ \\
\hline \multicolumn{6}{|c|}{ Panel A: Overall } \\
\hline Effect & $\begin{array}{l}-0.89 * * * \\
(0.25)\end{array}$ & $\begin{array}{l}-0.90 * * * \\
(0.25)\end{array}$ & $\begin{array}{l}-1.23 * * * \\
(0.40)\end{array}$ & $\begin{array}{l}-1.23 * * * \\
(0.39)\end{array}$ & $\begin{array}{c}0.32 \\
(0.43)\end{array}$ \\
\hline \%-change & -2.67 & -2.71 & -3.67 & -3.67 & 1.00 \\
\hline \multicolumn{6}{|c|}{ Panel B: Age 15-19 } \\
\hline Effect & $\begin{array}{r}-0.21 \\
(0.68)\end{array}$ & $\begin{array}{c}-0.09 \\
(0.68)\end{array}$ & $\begin{array}{c}0.46 \\
(0.98)\end{array}$ & $\begin{array}{c}0.46 \\
(0.96)\end{array}$ & $\begin{array}{r}-0.41 \\
(0.78)\end{array}$ \\
\hline$\%$-change & -0.53 & -0.24 & 1.19 & 1.19 & -1.05 \\
\hline \multicolumn{6}{|c|}{ Panel C: Age 20-24 } \\
\hline Effect & $\begin{array}{c}0.35 \\
(0.37)\end{array}$ & $\begin{array}{c}0.29 \\
(0.38)\end{array}$ & $\begin{array}{c}0.18 \\
(0.39)\end{array}$ & $\begin{array}{c}0.18 \\
(0.39)\end{array}$ & $\begin{array}{r}-0.23 \\
(0.63)\end{array}$ \\
\hline$\%$-change & 1.46 & 1.22 & 0.73 & 0.73 & -0.92 \\
\hline \multicolumn{6}{|c|}{ Panel D: Age 25-29 } \\
\hline Effect & $\begin{array}{l}-0.81 * * \\
(0.28)\end{array}$ & $\begin{array}{l}-0.94 * * * \\
(0.27)\end{array}$ & $\begin{array}{l}-1.98 * * * \\
(0.47)\end{array}$ & $\begin{array}{l}-1.98 * * * \\
(0.46)\end{array}$ & $\begin{array}{c}0.09 \\
(0.76)\end{array}$ \\
\hline$\%$-change & -3.46 & -3.98 & -8.04 & -8.04 & 0.39 \\
\hline \multicolumn{6}{|c|}{ Panel E: Age 30+ } \\
\hline Effect & $\begin{array}{l}-1.08 * * * \\
(0.26)\end{array}$ & $\begin{array}{l}-1.05 * * * \\
(0.26)\end{array}$ & $\begin{array}{l}-1.38 * * * \\
(0.45)\end{array}$ & $\begin{array}{l}-1.38 * * * \\
(0.44)\end{array}$ & $\begin{array}{c}0.43 \\
(0.49)\end{array}$ \\
\hline \%-change & -3.14 & -3.07 & -4.00 & -4.00 & 1.32 \\
\hline
\end{tabular}

Note: The table displays the effect of the Bavarian bar hour extension on January 1, 2005, on the monthly number of alcohol-related hospitalizations per 100,000 inhabitants for various age groups, together with its standard error clustered on the state level (in parentheses). The sample is based on information of 388 counties covering the years 2003-2005, i.e. 13,968 county-month observations. The last line in each panel indicates the percentage change in alcohol-related hospitalizations due to the reform. All regressions are weighted by the population of the respective age group in the county. The first column displays the results of a basic difference-in-differences specification, the second column includes county and time fixed effects. Additionally, the third column includes time-varying control variables on the county and state level. The forth column adds state-specific seasonal dummies and the last column includes county-specific linear time trends. ${ }^{*} p<0.1 ;{ }^{* *} p<0.05 ;{ }^{* * *} p<0.01$. 
Table A.2: $p$-values according to different procedures

\begin{tabular}{|c|c|c|c|c|c|}
\hline \multirow[t]{2}{*}{ Age } & \multirow[t]{2}{*}{ Clustering } & \multicolumn{2}{|c|}{ Wild cluster bootstrap } & \multicolumn{2}{|c|}{ Panel corrected } \\
\hline & & Mammen weights & Rademacher weights & Independent & $\mathrm{AR}(1)$ \\
\hline Overall & 0.000 & 0.000 & 0.000 & 0.048 & 0.104 \\
\hline $15-19$ & 0.011 & 0.022 & 0.000 & 0.022 & 0.026 \\
\hline $20-24$ & 0.005 & 0.000 & 0.000 & 0.012 & 0.015 \\
\hline $25-29$ & 0.748 & 0.772 & 0.806 & 0.778 & 0.779 \\
\hline $30+$ & 0.391 & 0.392 & 0.326 & 0.630 & 0.709 \\
\hline
\end{tabular}

Note: The table displays $p$-values for the preferred specification (Table 2, last column) according to different computation procedures. The first column shows $p$-values based on clustered standard errors, which is the default option in this study. The second and third column display $p$-values based on wild cluster bootstrap-t procedures (1,000 replications, estimated under $\mathrm{H}_{1}$ ) as described in Cameron et al. (2008). The two columns differ only with respect to the weights that are used to compute the residuals: The second column relies on Mammen weights and the third column on Rademacher weights (see Cameron et al. (2008) for the details). The last two columns show $p$-values based on panel-corrected standard errors: the fourth column assumes that standard errors are heteroskedastic and contemporaneously correlated across counties but not autocorrelated, while the fifths column allows for a first-order autocorrelation process that all counties have in common. 
Figure A.2: Trends in alcohol-related hospitalizations - various control groups

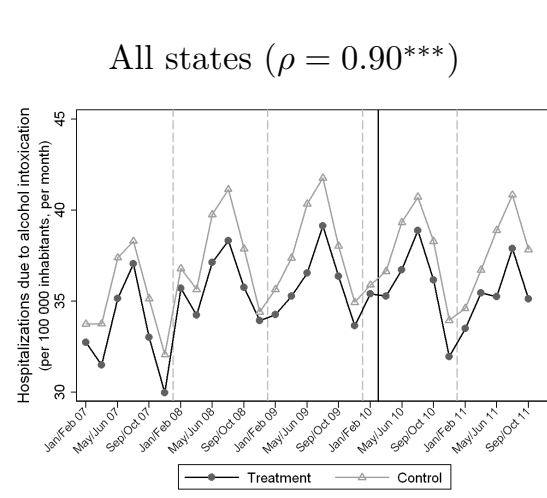

All states $\left(\rho=0.67^{* * *}\right)$

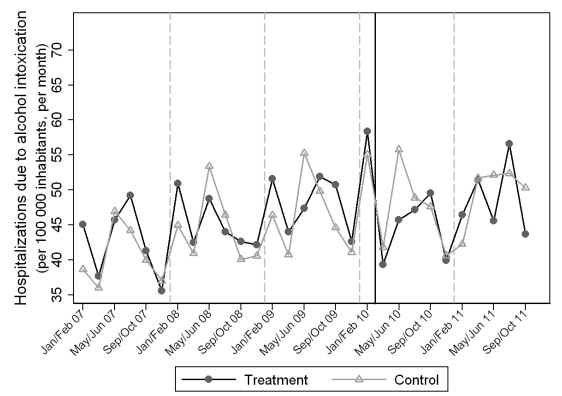

All states $\left(\rho=0.57^{* * *}\right)$

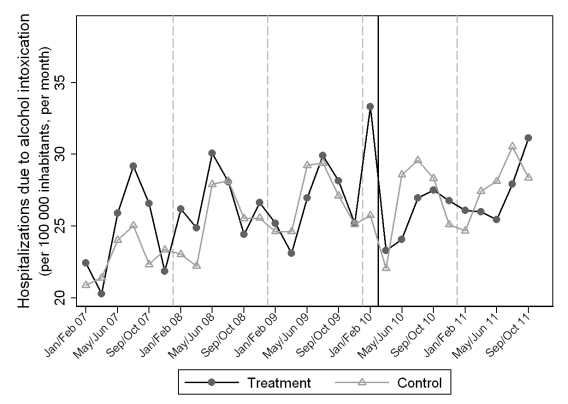

Western $\underset{\left(\rho=0.91^{* * *}\right)}{\text { Panel A: Overall }} \underset{\text { Southern }}{\left(\rho=0.84^{* * *}\right)}$

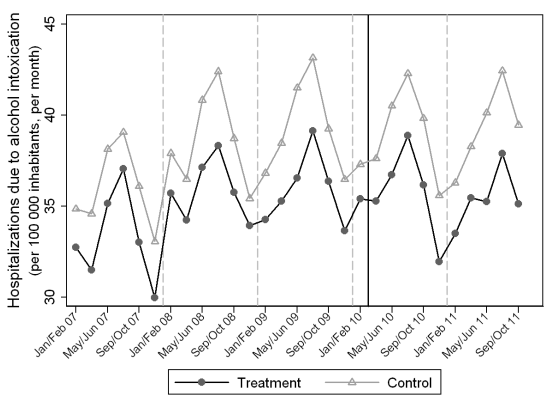

Panel B: Age 15-19

Western $\left(\rho=0.69^{* * *}\right)$

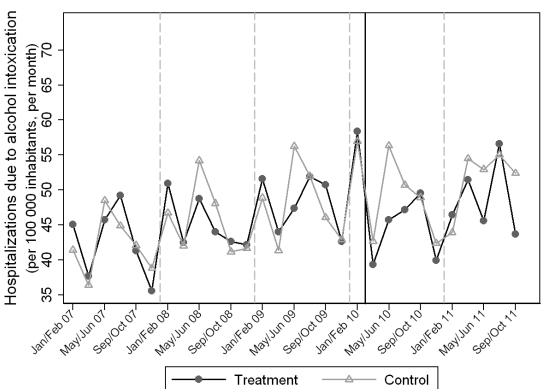

Panel C: Age 20-24

Western $\left(\rho=0.59^{* * *}\right)$

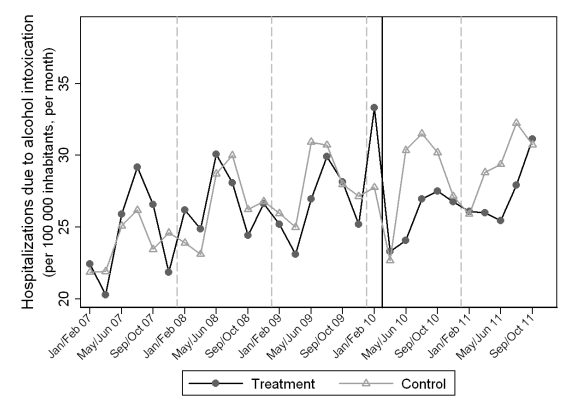

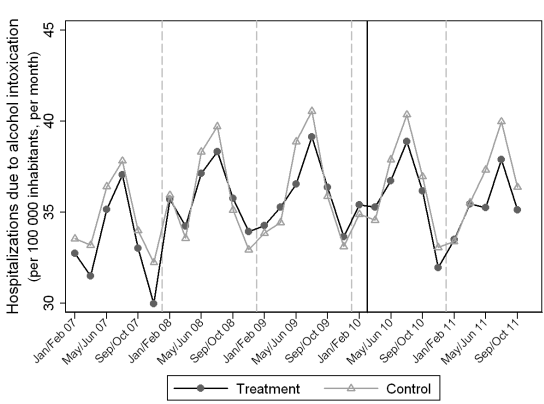

Southern $\left(\rho=0.77^{* * *}\right)$

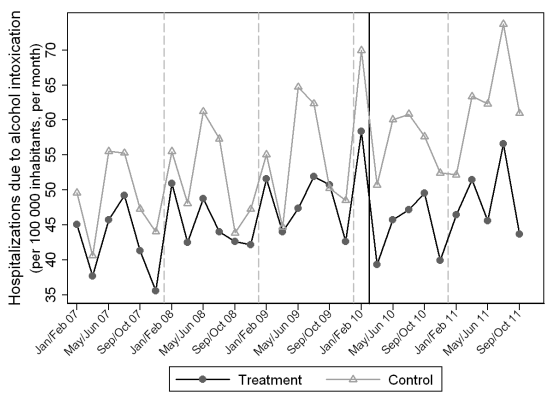

Synthetic $\left(\rho=1.00^{* * *}\right)$

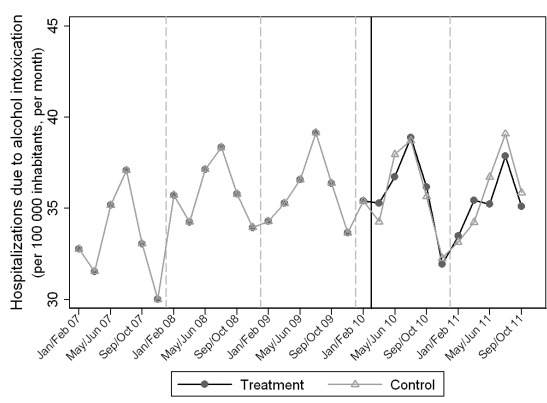

Synthetic $\left(\rho=1.00^{* * *}\right)$

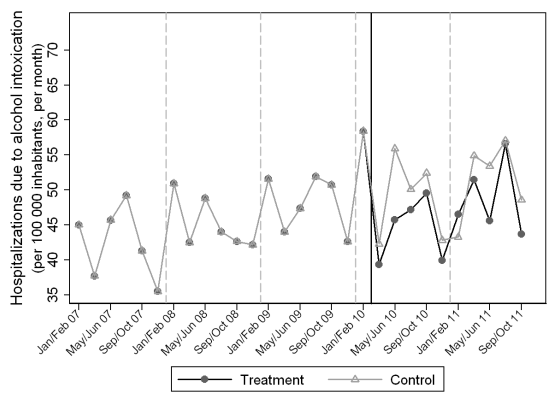

Synthetic $\left(\rho=1.00^{* * *}\right)$
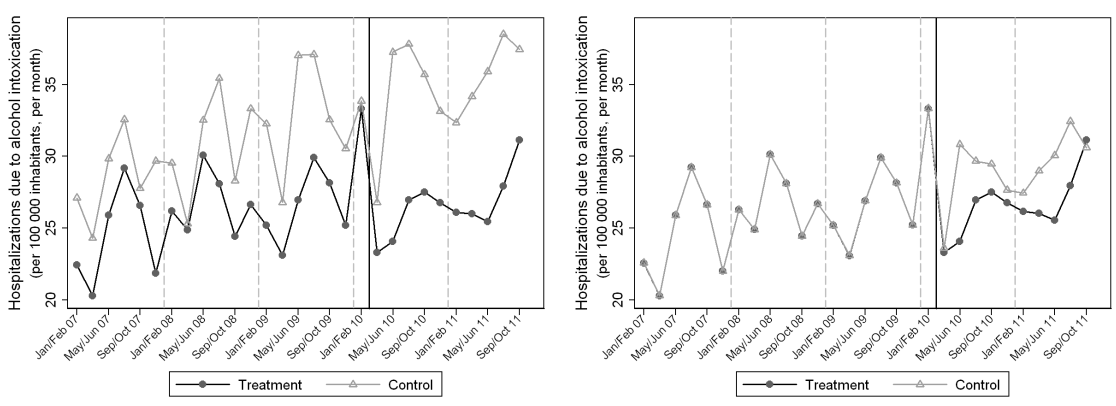
Figure A.2: Trends in alcohol-related hospitalizations - various control groups
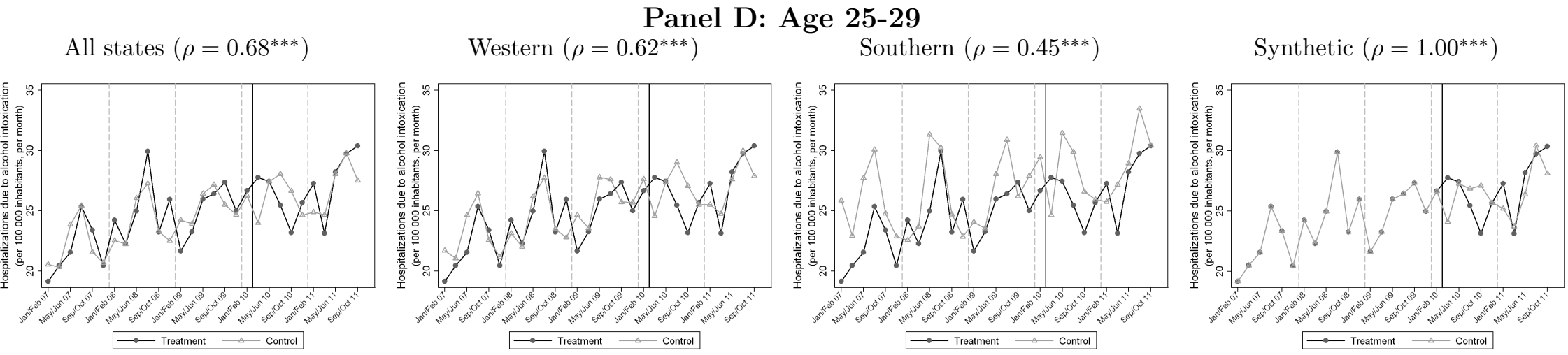

All states $\left(\rho=0.92^{* * *}\right)$

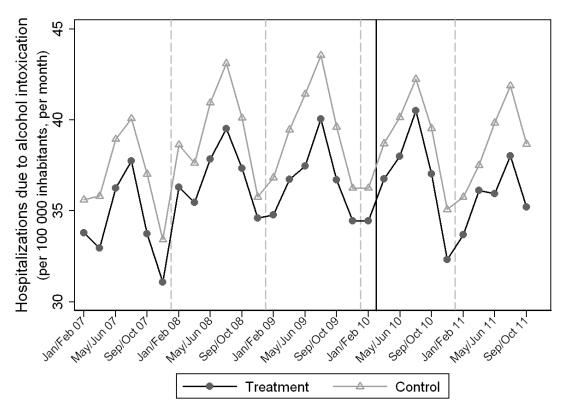

Panel E: Age 30+

Western $\left(\rho=0.93^{* * *}\right)$

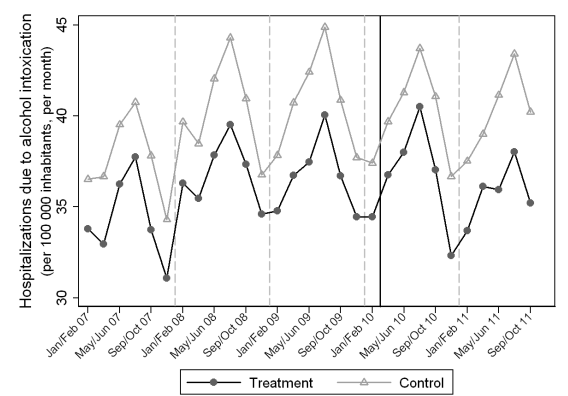

Southern $\left(\rho=0.85^{* * *}\right)$

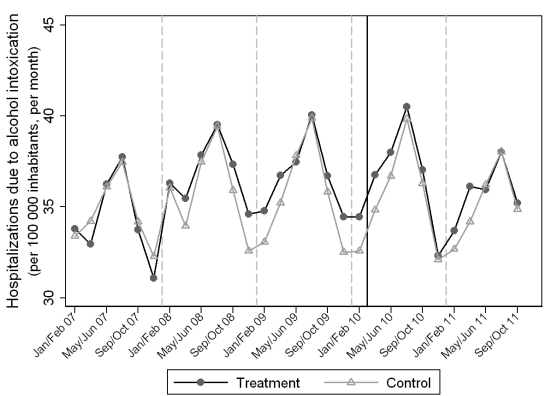

Synthetic $\left(\rho=1.00^{* * *}\right)$

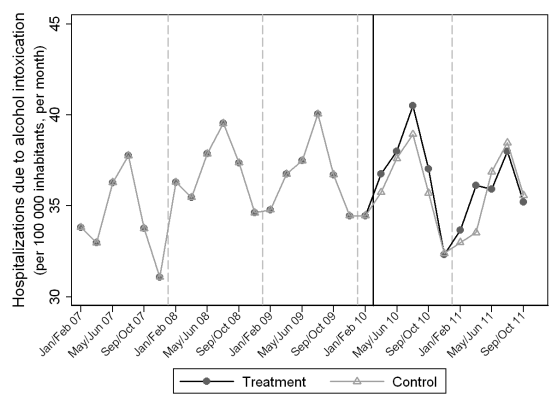

Note: The figure presents trends in the number of monthly alcohol-related hospitalizations per 100,000 same-aged inhabitants for the treatment group and various control groups (all states, western states, southern states, synthetic control), averaged over two months. The continuous vertical line shows the onset of the late-night ban on alcohol sales in the treatment state on March 01, 2010. $\rho$ indicates the pre-treatment correlation between the ARH-rates in the treatment group and the respective control group. $* p<0.1 ; * *$ $p<0.05$; *** $p<0.01$. 
Figure A.3: Proportion of young people binge drinking at home

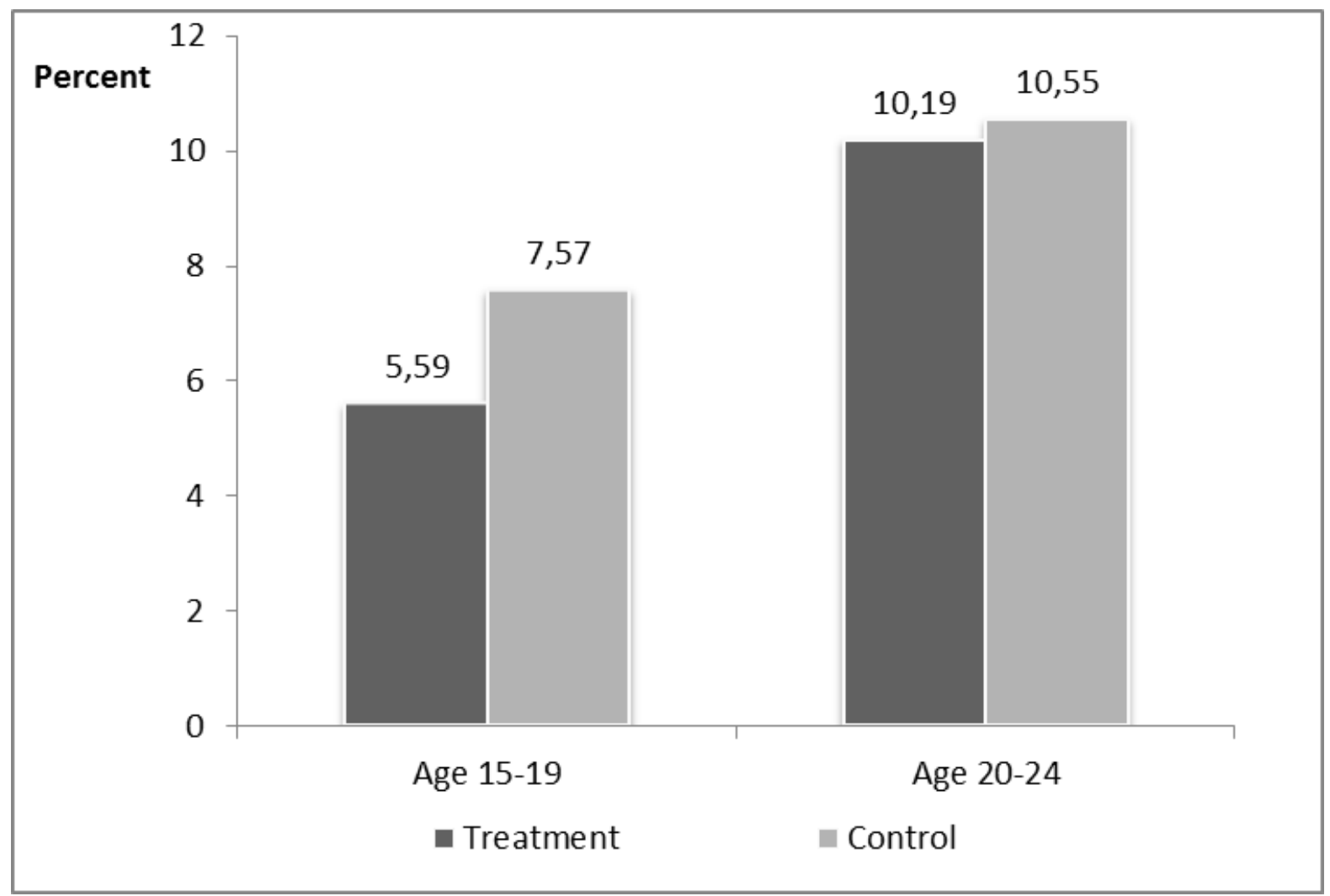

The figure displays the share of heavy alcohol consumers who state that they mainly binge drink at home. Source: Bundeszentrale für Gesundheitliche Aufklärung (BZgA). Representative survey among youth and young adults aged 12-25 in 2010. Interviews were conducted between June and August 2010. In this survey, young people were asked whether they were drinking alcohol in the last 30 days. In case they say yes, respondents were also asked the following question: "In case you drink more alcohol, with more I mean five drinks or more, where do you mainly drink?". Among the answer categories, respondents could name the location "at home". 
Figure A.4: The ban's effect on ARH rates - further ages

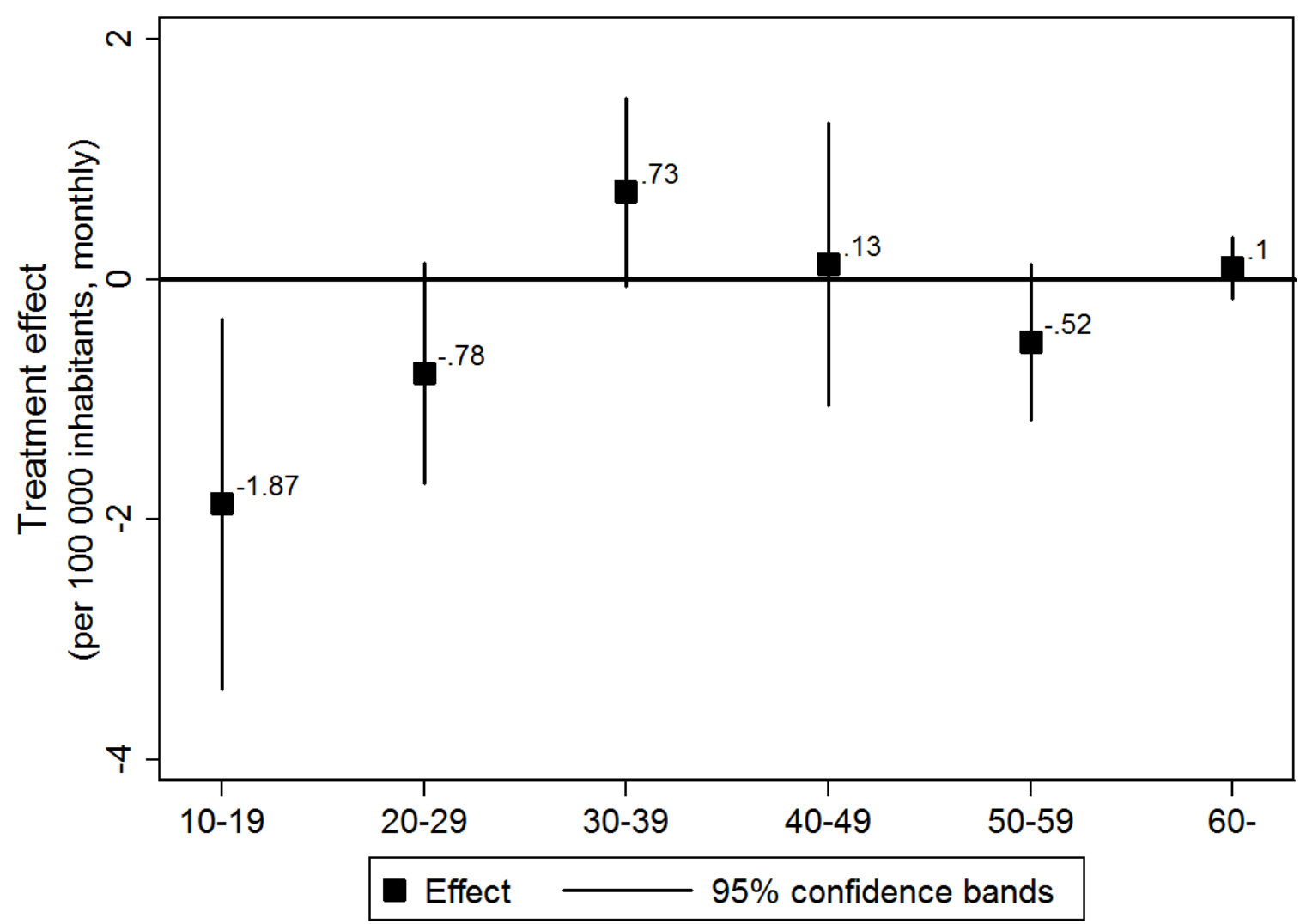

Note: The figure displays the ban's effect on alcohol-related hospitalization rates for 10-year age groups (see specification four of Table 2). 


\section{References}

Becker, Gary S. and Kevin M. Murphy, "A theory of rational addiction," Journal of Political Economy, 1988, 96 (4), 675-700.

Birckmayer, J. and D. Hemenway, "Minimum-age drinking laws and youth suicide, 1970-1990," American Journal of Public Health, 1999, 89 (9), 1365-1368.

Bouthoorn, Selma H., Joris J. van Hoof, and Nicolaas van der Lely, "Adolescent alcohol intoxication in Dutch hospital centers of pediatrics: Characteristics and gender differences.," European Journal of Pediatrics, August 2011, 170 (8), 1023-1030.

Bryan, Gharad, Dean Karlan, and Scott Nelson, "Commitment devices," Annual Review of Economics, September 2010, 2 (1), 671-698.

BZgA, Die Drogenaffinität Jugendlicher in der Bundesrepublik Deutschland 2011, Köln: Bundeszentrale für gesundheitliche Aufklärung [German Federal Centre for Health Education], 2012.

Cameron, Colin, Jonah B. Gelbach, and Douglas L. Miller, "Bootstrap-based improvements for inference with clustered errors," Review of Economics and Statistics, August 2008, 90 (3), 414-427.

Carpenter, Christopher S., "Heavy alcohol use and the commission of nuisance crime: Evidence from underage drunk driving laws," American Economic Review, 2005, 95 (2), $267-272$.

_ , "Youth alcohol use and risky sexual behavior: Evidence from underage drunk driving laws," Journal of Health Economics, May 2005, 24 (3), 613-628.

_ , Deborah D. Kloska, Patrick O'Malley, and Lloyd Johnston, "Alcohol control policies and youth alcohol consumption: Evidence from 28 years of Monitoring the Future," B.E. Journal of Economic Analysis 6 Policy, January 2007, 7 (1).

Carrell, Scott E., Mark Hoekstra, and James E. West, "Does drinking impair college performance? Evidence from a regression discontinuity approach," Journal of Public Economics, February 2011, 95 (1-2), 54-62.

Cawley, John and Christopher J Ruhm, The economics of risky health behaviors, Vol. 2, Elsevier, 2012.

CDU Baden-Württemberg, "In der Tat besser. Regierungsprogramm der CDU BadenWürttemberg 2006-2011," 2006, pp. 1-87. 
Chaloupka, Frank J. and Xin Xu, "The effects of prices on alcohol use and its consequences," Alcohol Research and Health, 2011, 34 (2), 236-245.

Chikritzhs, Tanya and Tim Stockwell, "The impact of later trading hours for hotels on levels of impaired driver road crashes and driver breath alcohol levels," Addiction, 2006, 101 (9), 1254-1264.

Conover, Emily and Dean Scrimgeour, "Health consequences of easier access to alcohol: New Zealand evidence," Journal of Health Economics, May 2013, 32 (3), 570585.

Cook, Philip J. and Michael J. Moore, "Alcohol," in Anthony Culyer and Joseph Newhouse, eds., Handbook of Health Economics, Vol. 1, Amsterdam: Elsevier, 2000, pp. $1631-1673$.

_ and _ , "The economics of alcohol abuse and alcohol-control policies," Health Affairs, 2002, 21 (2), 120-133.

Crost, Benjamin and Santiago Guerrero, "The effect of alcohol availability on marijuana use: Evidence from the minimum legal drinking age," Journal of Health Economics, January 2012, 31 (1), 112-121.

Dee, Thomas S., "State alcohol policies, teen drinking and traffic fatalities," Journal of Public Economics, May 1999, 72 (2), 289-315.

DHS, Binge drinking and Europe, Hamm: Deutsche Hauptstelle für Suchtfragen e.V. (DHS), January 2008.

Donald, Stephen G. and Kevin Lang, "Inference with difference-in-differences and other panel data," Review of Economics and Statistics, May 2007, 89 (2), 221-233.

Draca, Mirko, Stephen Machin, and Robert Witt, "Panic on the streets of London: Police, crime, and the July 2005 terror attacks," American Economic Review, August 2011,101 (5), 2157-2181.

Enoch, Mary-Anne, "Genetic and environmental influences on the development of alcoholism: Resilience vs. risk.," Annals of the New York Academy of Sciences, December 2006, 1094, 193-201.

FDZ, Krankenhausdiagnosestatistik, Erhebungsjahre 2007-2011, FDZ der Statistischen Ämter des Bundes und der Länder, 2014. 
Grossman, Michael, Jody L. Sindelar, John Mullahy, and Richard Anderson, "Policy watch: Alcohol and cigarette taxes," Journal of Economic Perspectives, 1993, $7(4), 211-222$.

Grundel, Anna and Beate Blättner, Entschädigung von Opfern interpersoneller Gewalt im Raum Fulda. Studie zum Opferentschädigungsgesetz (OEG) und der Verfahrenspraxis in der Opferentschädigung, Fulda: University of Applied Science Fulda, 2010.

Hainmueller, Jens, "Entropy balancing for causal effects: A multivariate reweighting method to produce balanced samples in observational studies," Political Analysis, October 2012, 20 (1), 25-46.

Heaton, Paul, "Sunday liquor laws and crime," Journal of Public Economics, February 2012, $96(1-2), 42-52$.

Hinnosaar, Marit, "Time inconsistency and alcohol sales restrictions," Technical Report, mimeo, Northwestern University 2012.

Hoffmann, Kevin, "Vorglühen an der Tankstelle," Der Tagesspiegel, 2009, 5 March 2009.

Hoischen, Oliver and Philip Eppelsheim, "Alkoholverbot an Tankstellen: Einmal volltanken, bitte!," Frankfurter Allgemeine Zeitung, 2009, 8 June 2009.

Hwang, Stephen W., Mohammad M. Agha, Maria I. Creatore, and Richard H. Glazier, "Age- and sex-specific income gradients in alcohol-related hospitalization rates in an urban area," Annals of Epidemiology, January 2005, 15 (1), 56-63.

Kanny, Dafna, Yong Liu, Robert D. Brewer, William S. Garvin, and Lina Balluz, "Vital signs: Binge drinking prevalence, frequency, and intensity among adults - United States, 2010," Morbidity and Mortality Weekly Report (MMWR), 2012, 61 (1), 14-19.

Kelly, Elaine and Imran Rasul, "Policing cannabis and drug related hospital admissions: Evidence from administrative records," Journal of Public Economics, April 2014, 112, 89-114.

Kim, Jason Y., Sumeet K. Asrani, Nilay D. Shah, W. Ray Kim, and Terry D. Schneekloth, "Hospitalization for underage drinkers in the United States," Journal of Adolescent Health, 2012, 50 (6), 648-650. 
Landtag von Baden-Württemberg, "Gesetzbeschluss der Landesregierung. Gesetz zur Abwehr alkoholbeeinflusster Störungen der öffentlichen Sicherheit und Ordnung während der Nachtzeit und zum Schutz vor alkoholbedingten Gesundheitsgefahren (Alkoholverkaufsverbotsgesetz)," Technical Report, State Parliamant of BadenWürttemberg, Drucksache [printed matter] 14 / 5413, 2009.

_ , "Gesetzentwurf der Landesregierung. Gesetz zur Abwehr alkoholbeeinflusster Störungen der öffentlichen Sicherheit und Ordnung während der Nachtzeit und zum Schutz vor alkoholbedingten Gesundheitsgefahren (Alkoholverkaufsverbotsgesetz)," Technical Report, State Parliamant of Baden-Württemberg, Drucksache [printed matter] 14 / 4850, 2009.

_ , "Plenarprotokoll 14 / 73, 30.07.2009," Technical Report, State Parliamant of BadenWürttemberg, 14. Wahlperiode, 73. Sitzung, 2009.

Lechner, Michael, "The estimation of causal effects by difference-in-difference methods," University of St. Gallen Department of Economics Working Paper Series, 2010, 28.

Lovenheim, Michael F. and Joel Slemrod, "The fatal toll of driving to drink: The effect of minimum legal drinking age evasion on traffic fatalities," Journal of Health Economics, January 2010, 29 (1), 62-77.

Manning, Willard G., Linda Blumberg, and Lawrence H. Moulton, "The demand for alcohol: The differential response to price," Journal of Health Economics, 1995, 14 (2), 123-148.

McMillan, Garnett P. and Sandra Lapham, "Effectiveness of bans and laws in reducing traffic deaths: Legalized Sunday packaged alcohol sales and alcohol-related traffic crashes and crash fatalities in New Mexico," American Journal of Public Health, November 2006, 96 (11), 1944-8.

Middleton, Jennifer Cook, Robert A. Hahn, Jennifer L. Kuzara, Randy Elder, Robert D. Brewer, Sajal Chattopadhyay, Jonathan Fielding, Timothy S. Naimi, Traci L. Toomey, and Briana Lawrence, "Effectiveness of policies maintaining or restricting days of alcohol sales on excessive alcohol consumption and related harms," American Journal of Preventive Medicine, December 2010, 39 (6), 575-589.

Mullahy, John and Jody L. Sindelar, "Employment, unemployment, and problem drinking," Journal of Health Economics, August 1996, 15 (4), 409-34. 
Newton, Alastair, Shah Jalal Sarker, Gurjinderpal S. Pahal, Eric van den Bergh, and Charles Young, "Impact of the new UK licensing law on emergency hospital attendances: A cohort study," Emergency Medical Journal, August 2007, 24 (8), 532-534.

Norström, Thor and Ole-Jørgen Skog, "Saturday opening of alcohol retail shops in Sweden: An experiment in two phases," Addiction, June 2005, 100 (6), 767-776.

O'Connell, H. and B. A. Lawlor, "Recent alcohol intake and suicidality - A neuropsychological perspective," Irish Journal of Medical Science, December 2005, 174 (4), 51-54.

Parry, Ian W. H., Sarah E. West, and Ramanan Laxminarayan, "Fiscal and externality rationales for alcohol policies," The B.E. Journal of Economic Analysis \& Policy, January 2009, 9 (1).

Popova, Svetlana, Norman Giesbrecht, Dennis Bekmuradov, and Jayadeep Patra, "Hours and days of sale and density of alcohol outlets: Impacts on alcohol consumption and damage - A systematic review," Alcohol and Alcoholism, 2009, 44 (5), $500-516$.

Ruhm, Christopher J., "Alcohol policies and highway vehicle fatalities," Journal of Health Economics, August 1996, 15 (4), 435-454.

Scribner, R., D. Mackinnon, and J. Dwyer, "The risk of assaultive violence and alcohol availability in Los Angeles county," American Journal of Public Health, 1995, 85 (3), 335-340.

Sen, Bisakha, "Can beer taxes affect teen pregnancy? Evidence based on teen abortion rates and birth rates," Southern Economic Journal, 2003, 70 (2), 328-343.

Speer, P., D. Gorman, E. Labouvie, and M. Ontkush, "Violent crime and alcohol availability: Relationships in an urban community," Journal of Public Health Policy, 1998, 19 (3), 303-318.

Stehr, Mark F., "The effect of Sunday sales of alcohol on highway crash fatalities," B.E. Journal of Economic Analysis $\&$ Policy, January 2010, 10 (1).

Stolle, Martin, Peter-Michael Sack, H. Spieles, and Rainer Thomasius, "Alkoholintoxikierte Kinder und Jugendliche in der Notfallversorgung Hamburger Krankenhäuser [Acute ethanol intoxication among children and adolescents in Hamburg, Ger- 
many]," Bundesgesundheitsblatt, Gesundheitsforschung, Gesundheitsschutz, September 2010, 53 (9), 910-916.

Task Force on Community Preventive Services, "Recommendations on maintaining limits on days and hours of sale of alcoholic beverages to prevent excessive alcohol consumption and related harms," American Journal of Preventive Medicine, December 2010, 39 (6), 605-606.

Vingilis, Evelyn, "Limits of hours of sales and service: Effects on traffic society," Transportation Research Circular, 2007, E-C123, 120-129.

_, A. I. McLeod, J. Seeley, R. E. Mann, D. Beirness, and C. P. Compton, "Road safety impact of extended drinking hours in Ontario," Accident Analysis and Prevention, May 2005, 37 (3), 549-556.

Wagenaar, Alexander C., Amy L. Tobler, and Kelli A. Komro, "Effects of alcohol tax and price policies on morbidity and mortality: A systematic review," American Journal of Public Health, November 2010, 100 (11), 2270-2278.

_ and Traci L. Toomey, "Effects of minimum drinking age laws: Review and analyses of the literature from 1960 to 2000," Journal of Studies on Alcohol and Drugs, 2002, 14, 206-225.

_, M. M. Maldonado-Molina, and Bradley H. Wagenaar, "Effects of alcohol tax increases on alcohol-related disease mortality in Alaska: Time-series analyses from 1976 to 2004," American Journal of Public Health, 2009, 99 (8), 1464-1470.

White, Aaron M., Ralph W. Hingson, I-Jen Pan, and Hsiao-Ye Yi, "Hospitalizations for alcohol and drug overdoses in young adults ages 18 - 24 in the United States, 1999 - 2008: Results from the nationwide inpatient sample," Journal of Studies on Alcohol and Drugs, September 2011, 72 (5), 774-86.

Wicki, Matthias and Gerhard Gmel, "Hospital admission rates for alcoholic intoxication after policy changes in the canton of Geneva, Switzerland," Drug and Alcohol Dependence, November 2011, 118 (2-3), 209-215.

Williams, J., Rosalie Liccardo Pacula, Frank J. Chaloupka, and Henry Wechsler, "Alcohol and marijuana use among college students: Economic complements or substitutes?," Health Economics, September 2004, 13 (9), 825-843.

World Health Organization, Global status report on alcohol and health 2014, Geneva: World Health Organization, 2014. 
Young, Douglas J. and Agnieszka Bielinska-Kwapisz, "Alcohol prices, consumption, and traffic fatalities," Southern Economic Journal, 2006, 72 (3), 690-703. 